\title{
Activity-Dependent Reconnection of Adult-Born Dentate Granule Cells in a Mouse Model of Frontotemporal Dementia
}

\author{
Julia Terreros-Roncal, ${ }^{1,2,3}$ Miguel Flor-García, ${ }^{1,2,3 *}$ Elena P. Moreno-Jiménez, ${ }^{1,2,3 *}$ - Noemí Pallas-Bazarra, ${ }^{1,2 *}$ \\ Alberto Rábano, ${ }^{4}$ Nirnath Sah, ${ }^{5}$ Henriette van Praag, ${ }^{5,6}$ Damiana Giacomini, ${ }^{7}$ Alejandro F. Schinder, ${ }^{7}$ Jesús Ávila, ${ }^{1,2}$ \\ and $\odot$ Maria Llorens-Martín ${ }^{1,2,3}$ \\ ${ }^{1}$ Department of Molecular Neuropathology, Centro de Biología Molecular “Severo Ochoa”, CBMSO, CSIC-UAM, 28049 Madrid, Spain, ${ }^{2}$ Center for \\ Networked Biomedical Research on Neurodegenerative Diseases (CIBERNED), 28031 Madrid, Spain, ${ }^{3}$ Department of Molecular Biology, Faculty of \\ Sciences, Universidad Autónoma de Madrid, 28049 Madrid, Spain, ${ }^{4}$ Neuropathology Department, CIEN Foundation, 28031 Madrid, Spain, ${ }^{5}$ Neuroplasticity \\ and Behavior Unit, Laboratory of Neurosciences, National Institute on Aging, National Institutes of Health, Baltimore, Maryland 21224, ${ }^{6}$ Department of \\ Biomedical Science, Charles E. Schmidt College of Medicine, and Brain Institute, Florida Atlantic University, Jupiter, Florida 33458, and ${ }^{7}$ Laboratorio de \\ Plasticidad Neuronal, Fundación Instituto Leloir-Instituto de Investigaciones Bioquímicas de Buenos Aires-Consejo Nacional de Investigaciones Científicas \\ y Técnicas (CONICET), C1405BWE Buenos Aires, Argentina
}

Frontotemporal dementia (FTD) is characterized by neuronal loss in the frontal and temporal lobes of the brain. Here, we provide the first evidence of striking morphological alterations in dentate granule cells (DGCs) of FTD patients and in a mouse model of the disease, $\mathrm{Tau}^{\mathrm{VLW}}$ mice. Taking advantage of the fact that the hippocampal dentate gyrus (DG) gives rise to newborn DGCs throughout the lifetime in rodents, we used RGB retroviruses to study the temporary course of these alterations in newborn DGCs of female Tau ${ }^{\mathrm{VLW}}$ mice. In addition, retroviruses that encode either PSD95:GFP or Syn:GFP revealed striking alterations in the afferent and efferent connectivity of newborn Tau ${ }^{\mathrm{VLW}}$ DGCs, and monosynaptic retrograde rabies virus tracing showed that these cells are disconnected from distal brain regions and local sources of excitatory innervation. However, the same cells exhibited a predominance of local inhibitory innervation. Accordingly, the expression of presynaptic and postsynaptic markers of inhibitory synapses was markedly increased in the DG of Tau ${ }^{\text {VLW }}$ mice and FTD patients. Moreover, an increased number of neuropeptide Y-positive interneurons in the DG correlated with a reduced number of activated egr- $1^{+}$DGCs in Tau ${ }^{\mathrm{VLW}}$ mice. Finally, we tested the therapeutic potential of environmental enrichment and chemoactivation to reverse these alterations in mice. Both strategies reversed the morphological alterations of newborn DGCs and partially restored their connectivity in a mouse model of the disease. Moreover, our data point to remarkable morphological similarities between the DGCs of Tau ${ }^{\mathrm{VLW}}$ mice and FTD patients.

Key words: dentate granule cells (DGCs); DREADD; environmental enrichment; frontotemporal dementia (FTD); rabies virus; RGB retrovirus

\section{Significance Statement}

We show, for the first time to our knowledge, that the population of dentate granule cells is disconnected from other regions of the brain in the neurodegenerative disease frontotemporal dementia (FTD). These alterations were observed in FTD patients and in a mouse model of this disease. Moreover, we tested the therapeutic potential of two strategies, environmental enrichment and chemoactivation, to stimulate the activity of these neurons in mice. We found that some of the alterations were reversed by these therapeutic interventions.

\section{Introduction}

Frontotemporal dementia (FTD) belongs to the frontotemporal lobar degeneration group of neurodegenerative disorders and is characterized by a marked loss of neurons in the frontal and temporal lobes of the brain. FTD-Tau is a FTD variant that belongs to the family of tauopathies (Spillantini and Goedert, 2000, 
2001; Buée et al., 2002; Gasparini et al., 2007). This variant is caused by mutations in MAPT, which encodes Tau protein (Ghetti et al., 1999, 2015; Goedert et al., 2000; Oliva, 2000; Alonso Adel et al., 2004). Several genetically engineered animal models of FTD-Tau carry specific mutations in MAPT (Lewis et al., 2000; Götz et al., 2001; Allen et al., 2002; Yoshiyama et al., 2007). One such model, Tau ${ }^{\mathrm{VLW}}$ mice, generated in our laboratory, carries three mutations, G272V (V), P301L (L), and R406W (W), on this gene (Lim et al., 2001). These pathogenic mutations increase the susceptibility of Tau to phosphorylation by brain kinases and are related to the neurotoxicity exerted by pathological forms of Tau (Cooper et al., 1995; Goedert et al., 1999; Jicha et al., 1999; Furukawa et al., 2000, 2003; Alonso Adel et al., 2004; Rubinsztein, 2016). Moreover, Tau ${ }^{\text {VLW }}$ mice show marked anatomic alterations in the hippocampus (Engel et al., 2008), one of the brain regions most severely affected in FTD patients (Laakso et al., 2000). Using Golgi staining, we report here, for the first time to our knowledge, on the similarity between the morphological alterations in the hippocampal dentate granule cells (DGCs) of FTD patients and Tau ${ }^{\mathrm{VLW}}$ mice.

The hippocampus has several unique anatomical and functional features. One of the most distinctive characteristics of this region is its capacity to generate new neurons throughout life (Altman and Das, 1965; Eriksson et al., 1998; Spalding et al., 2013; Moreno-Jiménez et al., 2019). This process, named adult hippocampal neurogenesis (AHN), gives rise to newborn DGCs, which are continuously incorporated to the classical and alternative hippocampal trisynaptic circuits (Toni et al., 2008; LlorensMartín et al., 2015). This process confers the hippocampal network an extraordinary degree of plasticity throughout life. Given that this region of the brain is markedly affected by neurodegenerative disorders (Moreno-Jiménez et al., 2019), AHN has become the cornerstone of numerous therapeutic strategies aimed at counteracting the decrease in neural plasticity that characterizes these conditions (Lazarov and Marr, 2010, 2013).

In fact, diverse processes encompassed by AHN, including the proliferation of neural precursors and the differentiation and survival of these cells, are altered in patients with Alzheimer's disease (Moreno-Jiménez et al., 2019) and in animal models of neurodegenerative diseases (Kuhn et al., 2007; Lazarov and Marr, 2010), including FTD (Schindowski et al., 2008; Llorens-Martín et al., 2011; Komuro et al., 2015). To perform an in-depth char-

340709 and AARG-17-528125 to M.L.-M.); the Association for Frontotemporal Degeneration (2016 Basic Science Pilot Grant Award to M.L.-M.); the Comunidad de Madrid (PEJD-2017-PRE/BMD-3439 to M.L.-M.); the Center for Networked Biomedical Research on Neurodegenerative Diseases (CIBERNED to J.A.); the Argentine Agency for the Promotion of Science and Technology (PICT2015-3814 and PICT2013-1685 to A.S.); the Howard Hughes Medical Institute (SIRS Grant 55007652 to A. S.); and the National Institute on Aging (Intramural Research Program to H.v.P.). Institutional grants from the Fundación Ramón Areces and Banco de Santander to the CBMSO are also acknowledged. The salary of E.P.M-J was supported by a predoctoral researcher contract from the Comunidad de Madrid (PEJD-2017-PRE/BMD-3439). The salary of J.T-R was supported by a predoctoral researcher contract from the Universidad Autónoma de Madrid (FPI-UAM-2017). The salary of M.F-G was supported by a predoctoral researcher contract (PRE2018-085233) associated with a grant funded by the Spanish Ministry of Economy and Competitiveness (SAF-2017-82185-R, principal investigator: M.L.-M.). We thank Enrique Terreros for designing Excel Macros to analyze the data, Esther García and Raquel Cuadros for technical assistance; the animal and confocal microscopy facilities of the CBMSO for help with diverse experimental protocols; R. Tsien (Howard Hughes Medical Institute Laboratories at the University of California, San Diego), C. Baum and A. Schambach (Hannover Medical School, Germany), A. Miyawaki (RIKEN Brain Science Institute, Saitama, Japan), C. Riecken (University Medical Center HamburgEppendorf), C. Lois (Cal Tech, Pasadena), B. Roth (University of North Carolina at Chapel Hill), F. Calegari (Center for Regenerative Therapies, Dresden, Germany), and FH. Gage (Salk Institute) for kindly providing the retroviral plasmids used in the experiments; and R. Sánchez and the patients and families for generously donating brain samples. Human samples were generously provided by the Biobanco del Hospital Universitario Reina Sofia (Córdoba, Spain) and the Banco de Tejidos de la Fundación CIEN (Madrid, Spain).

The authors declare no competing financial interests.

*M.F.-G., E.P.M.-J., and N.P.-B. contributed equally to this work.

Correspondence should be addressed to María Llorens-Martín at m.llorens@csic.es.

https://doi.org/10.1523/JNEUROSCI.2724-18.2019

Copyright $\odot 2019$ the authors acterization of the morphological and functional alterations of adult-born DGCs in an animal model of FTD, we used a combination of new retroviral approaches. Moreover, to trace the presynaptic innervation of adult-born DGCs, we used an RVsynaptophysin (Syn)-GTRgp retrovirus and an EnvA- $\Delta$ G-MCh rabies virus (Vivar et al., 2012).

Next, we tested the therapeutic potential of two distinct strategies, environmental enrichment (EE) and the selective chemoactivation of newborn DGCs, to reverse the morphological and functional alterations observed in Tau ${ }^{\mathrm{VLW}}$ mice. EE is one of the most potent positive modulators of the rate of AHN (van Praag et al., 2000; Brown et al., 2003), and the stimulatory actions on newborn DGCs caused by this manipulation are mimicked by chemoactivation of these cells during their so-called critical period (Temprana et al., 2015; Alvarez et al., 2016). To achieve the selective chemoactivation of newborn DGCs, we stereotaxically injected a retrovirus that encodes the Designer Receptor Exclusively Activated by Designer Drugs (DREADDs), hM3D, a modified excitatory human muscarinic M3 receptor (Alexander et al., 2009), into the DG of WT and Tau ${ }^{\mathrm{VLW}}$ mice. Our data revealed that both $\mathrm{EE}$ and chemoactivation led to a full reversal of the morphological alterations and partial reversal of the alterations in the connectivity of these cells caused by Tau ${ }^{\text {VLW }}$ overexpression.

\section{Materials and Methods}

\section{Experimental strategy}

We examined the morphological phenotype of the DGCs of FTD patients (Fig. 1). We performed Golgi staining of the hippocampus of a cohort of five control subjects and three FTD patients (Fig. 2A). To test the involvement of pathological forms of Tau in these alterations, we investigated whether these morphological alterations were present in Tau ${ }^{\mathrm{VLW}}$ mice, an animal model of FTD. We used Golgi staining (Fig. 1) ( $n=4$ female 4-month-old mice per genotype) and a combination of innovative retroviral vectors called RGB retroviruses (Fig. 3) (Schambach et al., 2006; Gomez-Nicola et al., 2014). We injected each of the three RGB viruses (which express Cerulean, Venus, or mCherry fluorescent proteins) at a different time point. This experimental design allows for the labeling of three subpopulations of adult-born DGCs of different ages $(2,4$, and 8 weeks of cell age) in the same animal. In RGB retrovirus experiments, five female mice were used per genotype. Animals were 7 weeks old at the time of stereotaxic injections.

Moreover, we investigated whether the morphological alterations observed in adult-born DGCs are accompanied by alterations in the connectivity of these cells. We injected retroviruses that encode either PSD95:GFP or Syn:GFP into the hippocampus of WT and Tau ${ }^{\mathrm{VLW}}$ mice (Fig. 4). These retroviruses allowed for the study of postsynaptic densities (PSDs) and the presynaptic active zone of adult-born DGCs as a measurement of the afferent and efferent connectivity of these cells, respectively. In these experiments, five female mice were used per genotype and type of retrovirus injected. Animals were 7 weeks old at the time of stereotaxic injections.

To study afferent innervation of adult-born DGCs, we applied the rabies virus TVA-EnvA retrograde trans-synaptic tracing method (Fig. 5) (Wickersham et al., 2007a,b). These experiments allowed the labeling of the cell populations that presynaptically innervate starter newborn DGCs (traced cells). In these experiments, five female mice were used per genotype. Animals were 7 weeks old at the time of stereotaxic injections. Given the increased innervation of adult-born DGCs by interneurons observed in Tau ${ }^{\mathrm{VLW}}$ mice, we next analyzed the expression of presynaptic and postsynaptic markers of inhibitory synapses in various regions of the DG of Tau ${ }^{\text {VLW }}$ mice and FTD patients as a measurement of the afferent inhibitory innervation of this structure (Fig. 6). Hippocampal samples from 5 control subjects and 3 FTD patients were analyzed, and 10 female (4-month-old) mice per genotype were used for staining. Moreover, we counted the number of different subpopulations of in- 

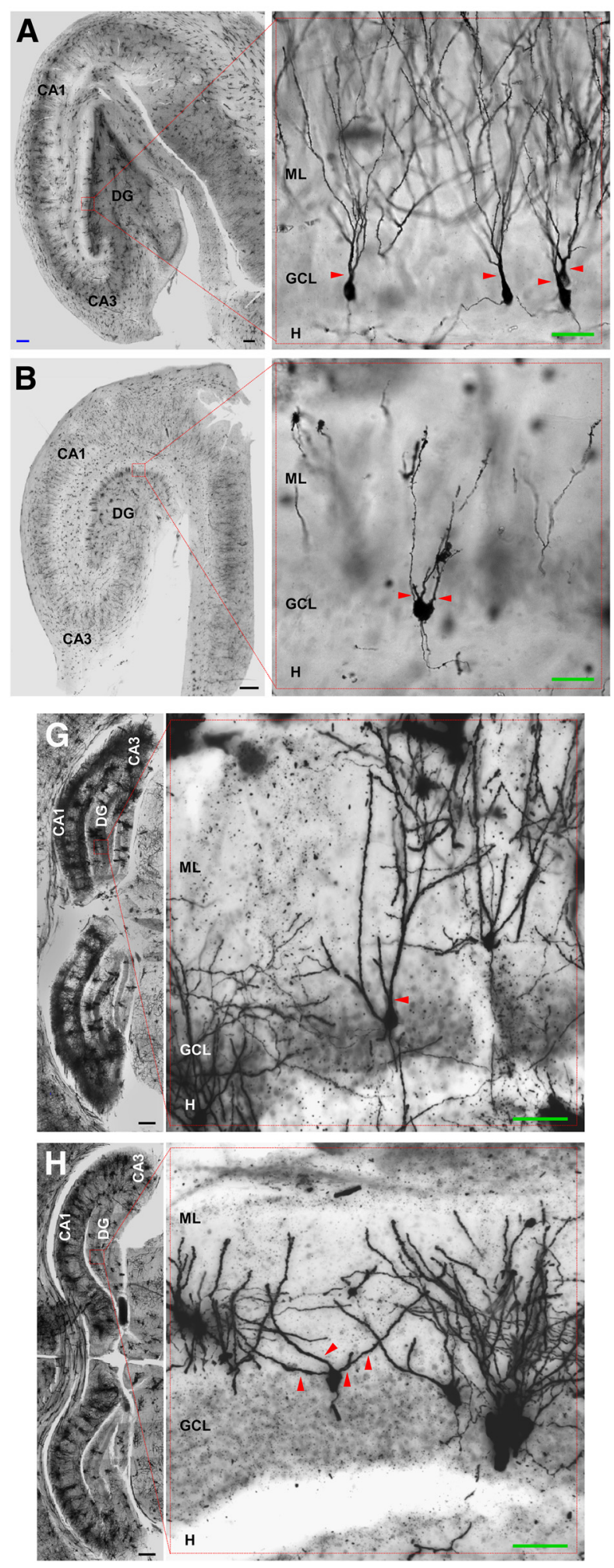

C

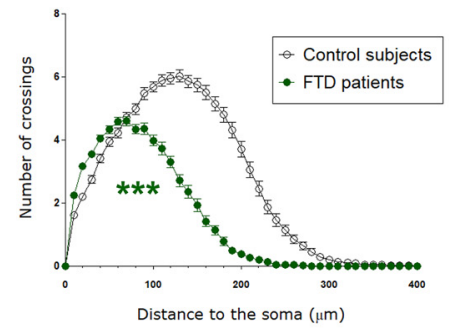

$\mathbf{D}$

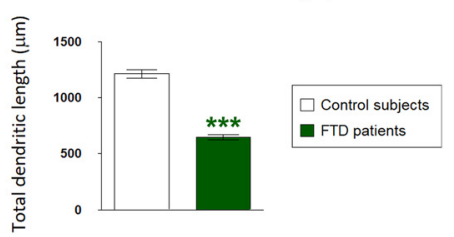

E

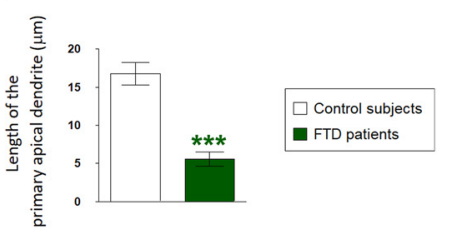

F

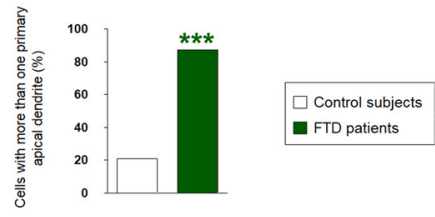

I

J

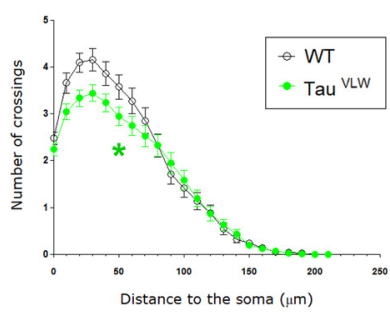

K
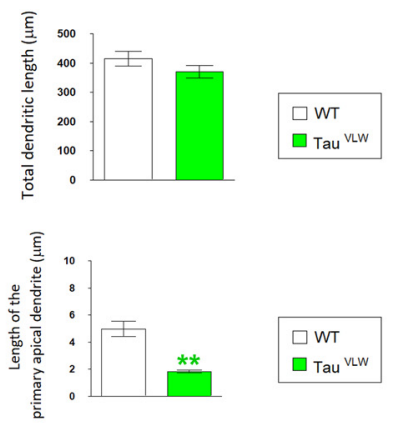

L

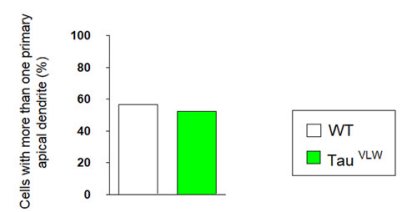

Figure 1. Golgi-stained DGCs of patients with FTD and of Tau ${ }^{\mathrm{VLW}}$ mice show similar morphological alterations. $A, B$, Representative confocal tilescans showing Golgi staining in the hippocampus of a control subject $(\boldsymbol{A})$ and a patient with FTD $(\boldsymbol{B})$. C, Sholl's analysis of Golgi-stained DGCS. $\boldsymbol{D}$, Measurement of total dendritic length. $\boldsymbol{E}$, Length of the primary apical dendrite of DGCs. $\boldsymbol{F}$, Percentage of cells with more than one primary apical dendrite. In $\boldsymbol{A}-\boldsymbol{F}, n=5$ control subjects and $3 \mathrm{FTD}$ patients. At least 25 cells were analyzed per subject. Asterisks indicate changes with respect to control subjects. $\mathbf{G}-\boldsymbol{H}$ : Representative confocal tilescans showing Golgi staining in the hippocampus of WT ( $\boldsymbol{G}$ ) and Tau ${ }^{\mathrm{VLW}}(\boldsymbol{H})$ mice. I, Sholl's analysis of Golgi-stained murine DGCs.J, Measurement of total dendritic length in murine DGCs. $\boldsymbol{K}$, Length of the primary apical dendrite of murine DGCs. $L$, Percentage of murine DGCs with more than one primary apical dendrite. In $\mathbf{G}-\boldsymbol{L}, n=4$ female mice per genotype. At least 25 cells were analyzed per animal. Asterisks indicate changes with respect to WT mice. DG: Dentate gyrus. GCL: Granule cell layer. ML, Molecular layer; H, hilus. Black scale bar: 100 $\mu \mathrm{m}$. Green scale bar: $50 \mu \mathrm{m}$. Red triangles: Primary apical dendrites. ${ }^{*} 0.05>p \geq 0.01 ;{ }^{* *} 0.01>p \geq 0.001 ;{ }^{* * *} 0.001>p$. 


\begin{tabular}{|c|c|c|c|c|c|c|c|c|}
\hline PATIENT CODE & AGE (YEARS) & GENDER & $\begin{array}{c}\text { POST-MORTEM } \\
\text { INTERVAL (HOURS) }\end{array}$ & CERAD & BRAAK-TAU & $\begin{array}{c}\text { BRAAK } \\
\alpha \text {-SYNUCLEIN }\end{array}$ & $\begin{array}{l}\text { VASCULAR } \\
\text { SCORE (0-3) }\end{array}$ & DIAGNOSE \\
\hline C 1 & 85 & MALE & 23 & 0 & 0 & 0 & - & CONTROL \\
\hline C 2 & 52 & FEMALE & 6 & 0 & 0 & 0 & 0 & CONTROL \\
\hline C 3 & 64 & MALE & 7 & 0 & 0 & 0 & - & CONTROL \\
\hline C4 & 75 & FEMALE & 5 & 0 & 0 & 0 & - & CONTROL \\
\hline C5 & 78 & MALE & 3 & 0 & 0 & 0 & - & CONTROL \\
\hline FTD 1 & 87 & FEMALE & 4 & A & 4 & 0 & 3 & FTD \\
\hline FTD 2 & 76 & MALE & 5 & B & 1 (ATYPICAL) & 0 & 1 & FTD \\
\hline FTD 3 & 73 & MALE & 10 & 0 & 2 & 0 & 1 & FTD \\
\hline
\end{tabular}

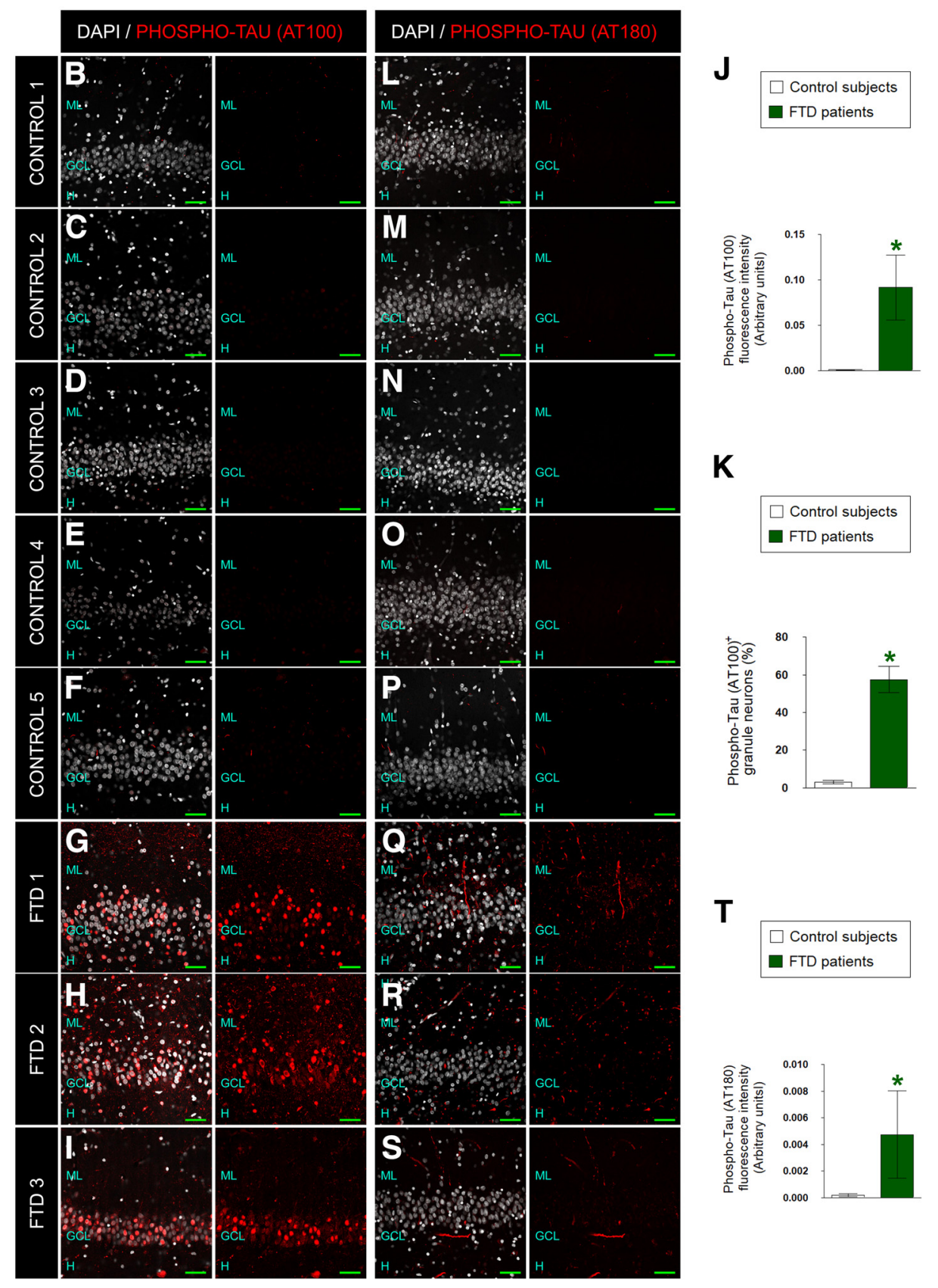

Figure 2. Epidemiological factors and phospho-Tau (AT100 and AT180) staining in the GCL of human subjects. $A$, Epidemiological factors. $\boldsymbol{B}$ - $\boldsymbol{I}$ and $\boldsymbol{L}$ - $\boldsymbol{S}$ are representative images of phospho-Tau $(A T 100, \boldsymbol{B}-\boldsymbol{I})(A T 180, \boldsymbol{L}-\boldsymbol{S})$ staining in the DG of human subjects. $\boldsymbol{J}$, Fluorescence intensity of phospho-Tau (AT-100) staining in the GCL. $\boldsymbol{K}$, Percentage of phospho-Tau (AT100) ${ }^{+}$DGCs. $\boldsymbol{T}$, Fluorescence intensity of Phopsho-Tau (AT-180) staining in the GCL. In $\boldsymbol{J}, \boldsymbol{K}$, and $\boldsymbol{T}, n=5$ control subjects and 3 FTD patients. Five stacks of images were analyzed per subject. Asterisks indicate changes with respect to control subjects. GCL, granule cell layer; ML, Molecular layer; H, Hilus. Green scale bar, $50 \mu \mathrm{m} .{ }^{*} 0.05>p \geq 0.01$.

terneurons [either parvalbumin-positive $\left(\mathrm{PV}^{+}\right)$or neuropeptide Y-positive $\left(\mathrm{NPY}^{+}\right)$; Fig. 7], together with the expression of markers of neuronal activation (cfos, Arc, or egr-1) (Fig. 8) in the DG of WT and $\mathrm{Tau}^{\mathrm{VLW}}$ mice. In these experiments, 10 female (4-month-old) mice were used per genotype.
We next explored the reversibility of the cellular alterations previously observed in Tau ${ }^{\mathrm{VLW}}$ adult-born DGCs. We used two strategies to increase the activation of these cells. First, we tested the therapeutic potential of a 2-month period of EE to reverse the alterations caused by mutated forms of Tau (Figs. 9 and 10). We tested the general responsivity 

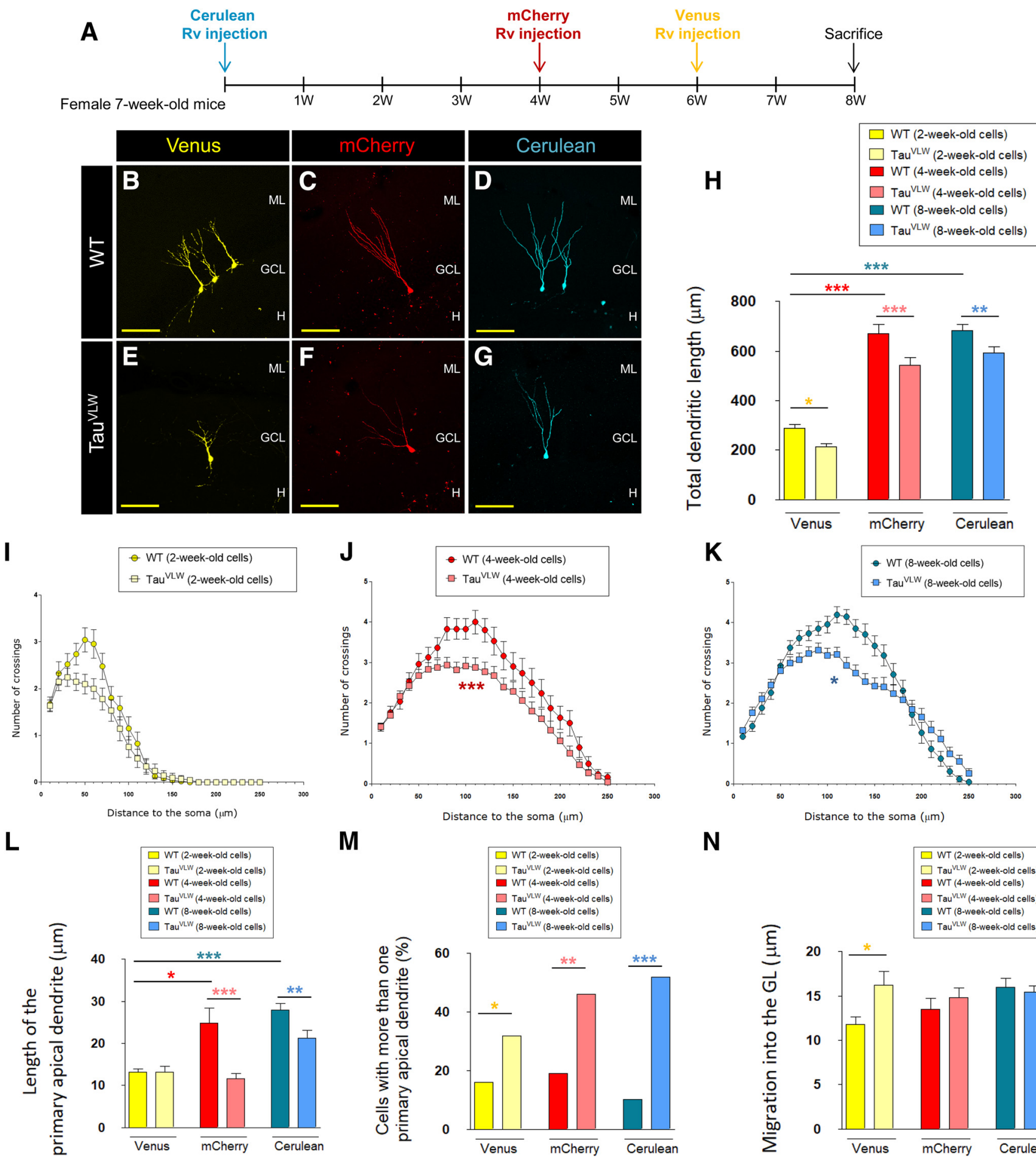

M

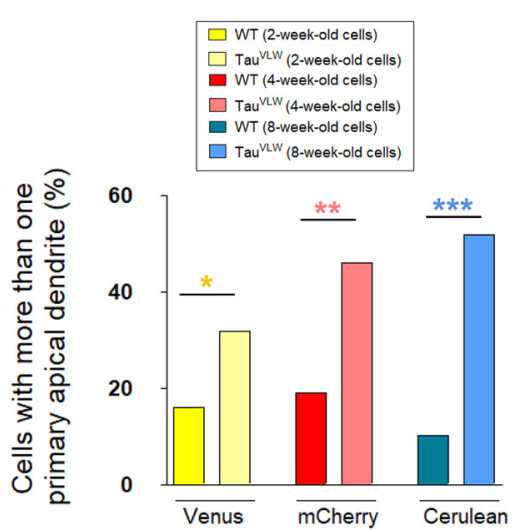

$\mathbf{N}$

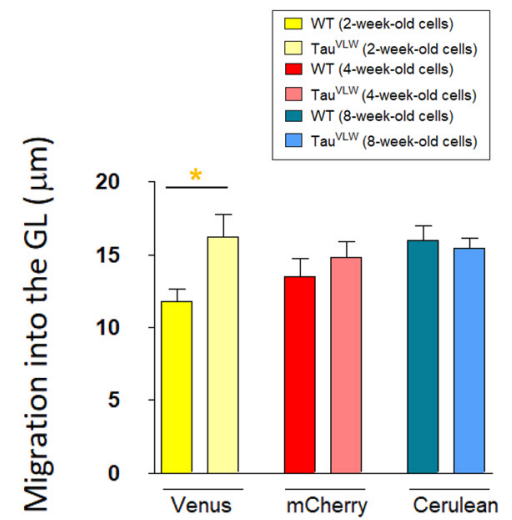

Figure 3. Newborn DGCs of Tau ${ }^{\mathrm{VLW}}$ mice show morphological alterations. $\boldsymbol{A}$, Experimental design. Each one of the three RGB retroviruses (Cerulean, mCherry, and Venus) was stereotaxically injected into the hippocampus of 7-week-old female WT and Tau ${ }^{\mathrm{VLW}}$ mice at a different time point, to label three populations of adult-born DGCs of different ages in the same animal. $\boldsymbol{B}$ - $\mathbf{G}$ : Representative images of adult-born DGCs transduced with Venus- $(\boldsymbol{B}, \boldsymbol{E}), \mathrm{mCherry}-(\boldsymbol{C}, \boldsymbol{F})$, or Cerulean $(\boldsymbol{D}, \boldsymbol{G})$-encoding retroviruses. $\boldsymbol{H}$, Total dendritic length. $\boldsymbol{I}$, Sholl's analysis of 2-week-old Venus ${ }^{+}$ adult-born DGCS.J, Sholl's analysis of 4-week-old mCherry ${ }^{+}$adult-born DGCS. $\boldsymbol{K}$, Sholl's analysis of 8-week-old Cerulean ${ }^{+}$adult-born DGCs. L, Length of the primary apical dendrite. $\boldsymbol{M}$, Percentage of cells with more than one primary apical dendrite. $\boldsymbol{N}$, Adult-born DGC migration into the granule cell layer (GCL). $\ln \boldsymbol{H}-\boldsymbol{N}, n=5$ female mice per genotype. At least 50 cells per cell age and genotype were analyzed. ML, Molecular layer; $H$, hilus. Yellow scale bar, $100 \mu \mathrm{m} .{ }^{*} 0.05>p \geq 0.01 ;{ }^{* *} 0.01>p \geq 0.001 ;{ }^{* * *} 0.001>p$.

of AHN in Tau ${ }^{\mathrm{VLW}}$ mice to the stimulatory effects of EE. For this purpose, we used thymidine analog injections and performed cell counts of several populations of cells in the DG. In these experiments, 10 female mice aged 7-8 weeks were used per genotype (Fig. 9). We also stereotaxically injected PSD95:GFP-encoding retroviruses into the hippocampus to test the reversibility of the morphological and functional alterations in newborn DGCs of Tau ${ }^{\mathrm{VLW}}$ mice. In these experiments, five female mice were used per genotype. Animals were 7 weeks old at the time of stereotaxic injections (Fig. 10).

In the second strategy, we tested the potential of a transient increase in the excitability of adult-born DGCs, achieved through chemoactivation during the critical period of these cells to counteract the cellular altera- 


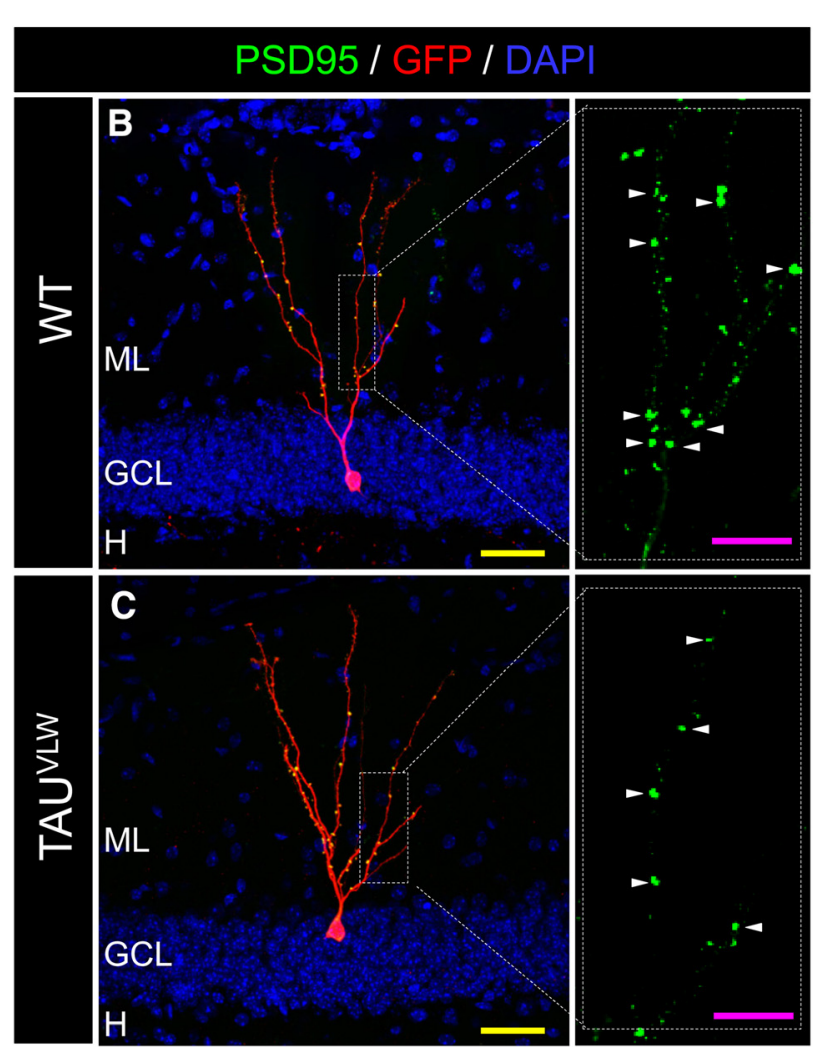

A

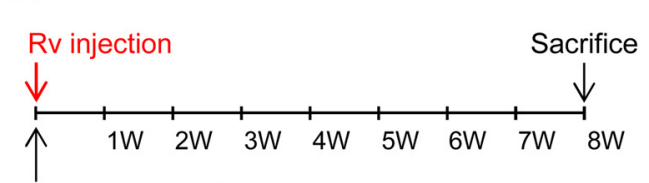

Female 7-week-old mice
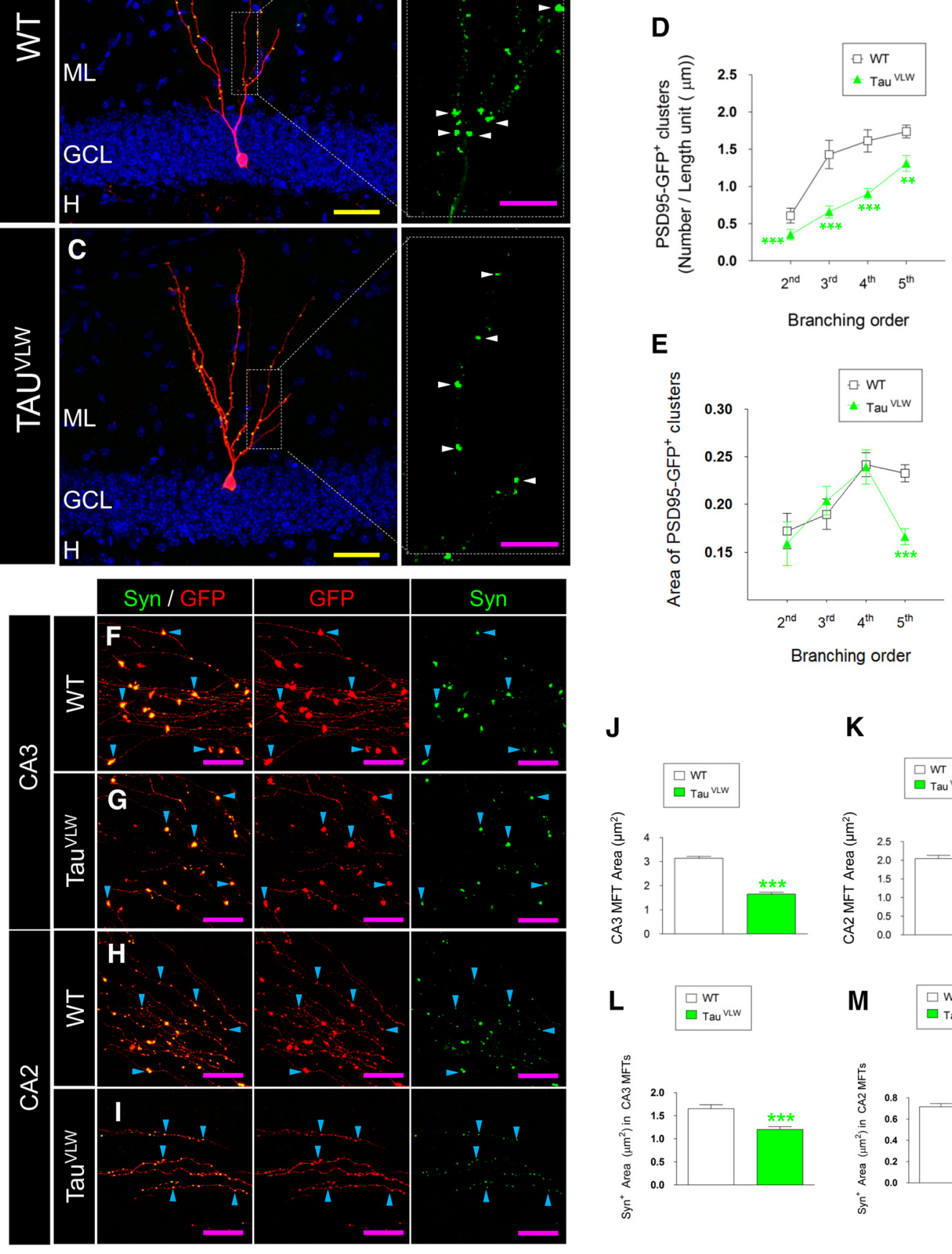

J
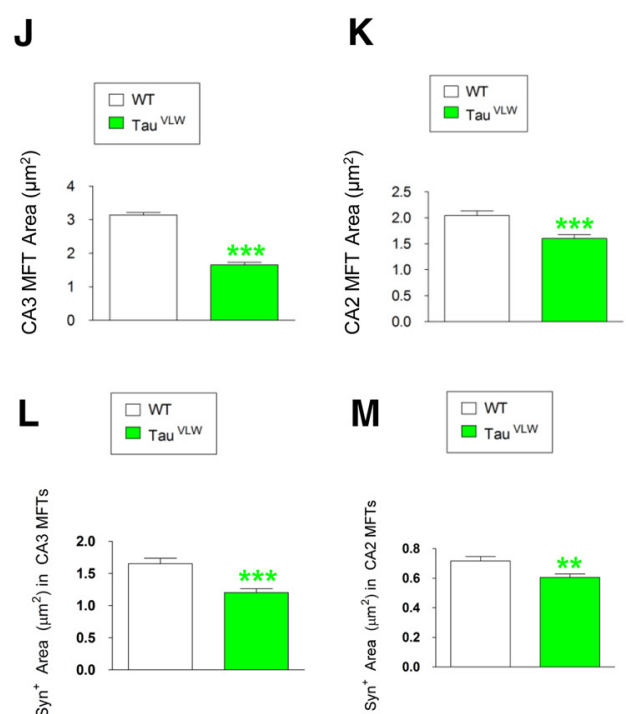

Figure 4. Newborn DGCS of Tau ${ }^{\text {VLW }}$ mice show altered afferent and efferent connectivity. $A$, Experimental design. PSD95:GFP or Syn:GFP (Syn:GFP) retroviruses were stereotaxically injected into the hippocampus of 7-week-old female WT and Tau ${ }^{\mathrm{VLW}}$ mice to study the afferent and efferent connectivity of these cells respectively. Animals were killed 8 weeks later. $B, C$, Representative images of PSD95:GFP-transduced cells and their respective high-power magnification images showing the presence of PSDs. D, Density of PSDs along the dendritic tree of adult-born DGCs. $\boldsymbol{E}$, Area of individual PSDs along the whole dendritic tree of adult-born DGCs. In $\mathbf{D}-\boldsymbol{E}, n=5$ female mice per genotype. At least 50 dendritic fragments per branching order and genotype were analyzed. Asterisks indicate changes with respect to WT animals. $\boldsymbol{F}, \boldsymbol{I}$, Representative high-power magnification images of MFTs of Syn:GFP-transduced adult-born DGCs in the CA3 $(\boldsymbol{F}, \boldsymbol{G})$ and the $C A 2(\boldsymbol{H}, \boldsymbol{I})$ regions. $J$, Area of individual MFTs in the CA3 region. $\boldsymbol{K}$, Area of individual MFTs in the CA2 region. $L$, Syn ${ }^{+}$area of MFTs in the CA3 region. $M$, Syn ${ }^{+}$area of MFTs in the CA2 region. In $J-M, n=5$ female mice per genotype. A minimum of 20 stacks of images per animal and region were obtained. A minimum of $400 \mathrm{MFTs}$ per area and genotype were analyzed. Asterisks indicate changes with respect to WT animals. GCL, granule cell layer; ML, Molecular layer; H, hilus. Yellow scale bar, $50 \mu \mathrm{m}$; pink scale bar, $10 \mu \mathrm{m}$. White triangles indicate PSDs; blue triangles, MFTs. ${ }^{* *} 0.01>p \geq 0.001$; ${ }^{* * *} 0.001>p$. 

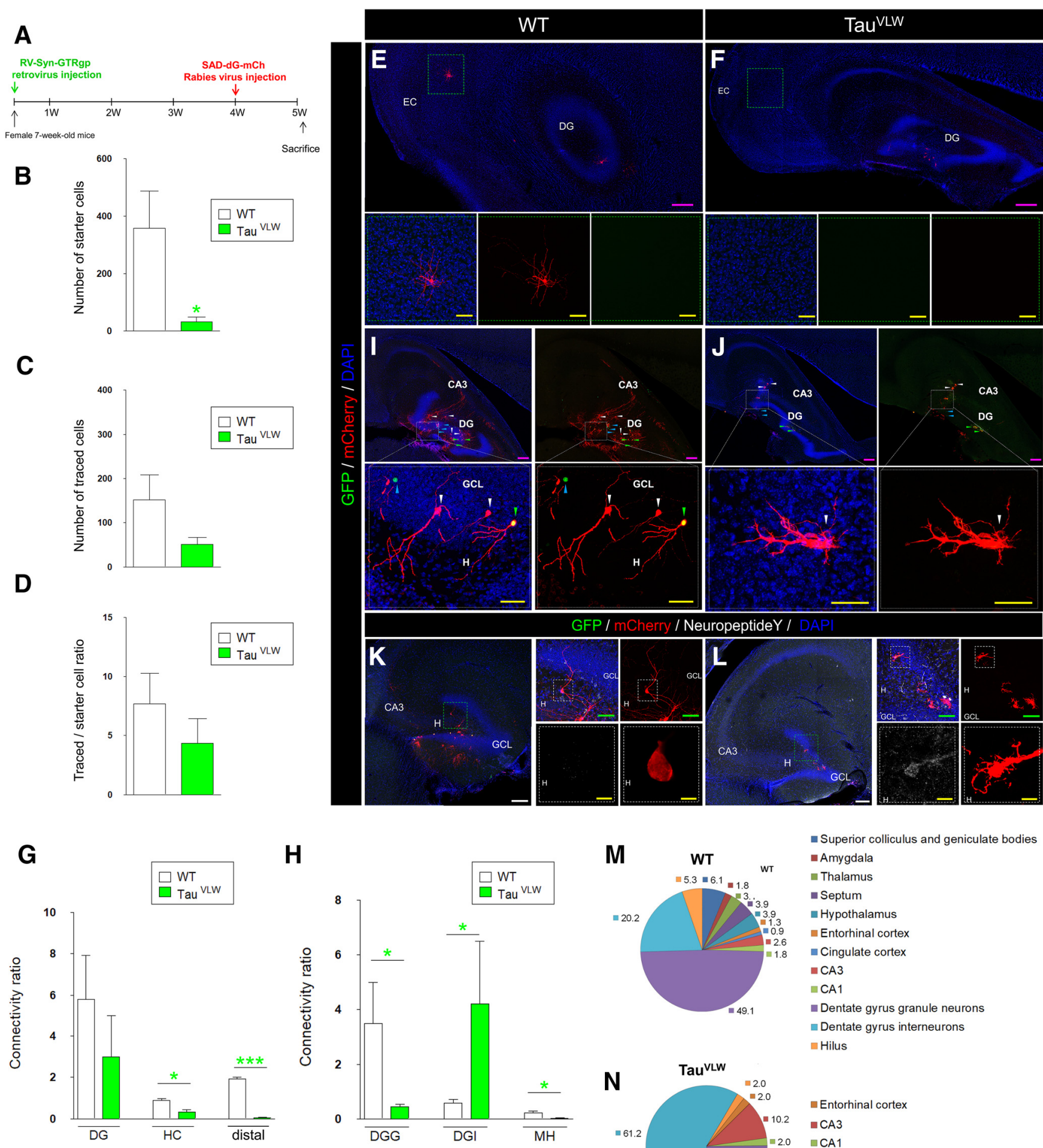

- Superior colliculus and geniculate bodies

- Amygdala

- Thalamus

- Septum

- Hypothalamus

mEntorhinal cortex

- Cingulate cortex

$\because \mathrm{CA} 3$

¿CA1

Dentate gyrus granule neurons

Dentate gyrus interneurons

-Hilus

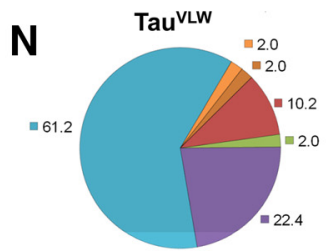

Entorhinal cortex

- $\mathrm{CA} 3$

๓CA1

- Dentate gyrus granule neurons

Dentate gyrus interneurons

घhilus

Figure 5. Newborn DGCS of Tau ${ }^{\mathrm{VLW}}$ mice show altered afferent innervation. $\boldsymbol{A}$, Experimental design. Briefly, RV-Syn-GTRgp retroviruses were stereotaxically injected into the hippocampus of 7-week-old female WT and Tau ${ }^{\text {VLW }}$ mice to label a population of starter adult-born DGCS. Four weeks later, an EnvA- $\Delta$ G-MCh rabies virus was stereotaxically injected to trace the cells innervating starter cells (traced cells). Animals were killed 1 week later. $\boldsymbol{B}$, Number of starter cells. C, Number of traced cells. $\boldsymbol{D}$, traced/starter cell ratio. $\boldsymbol{E}$, $\boldsymbol{F}$, Representative images of the hippocampus and entorhinal cortex (EC) of WT $(\boldsymbol{E})$ and Tau ${ }^{\mathrm{VLW}}(\boldsymbol{F})$ mice showing the presence of traced cells (red) in WT mice. $\boldsymbol{G}$, Connectivity ratio of local (DG), proximal (HC) and distal brain regions. $\boldsymbol{H}$, Connectivity ratio of dentate gyrus neuronal subpopulations: DGCS, DGls, and MH cells. $I, J$, Representative images of the DG of WT $(I)$ and Tau ${ }^{\mathrm{VLW}}(\boldsymbol{J})$ mice showing the innervation of starter cells by traced DGCS in WT animals $(\boldsymbol{I})$ and by traced inhibitory interneurons in Tau ${ }^{\mathrm{VLW}}(\boldsymbol{J})$ mice. $\boldsymbol{K}-\boldsymbol{L}$ : Representative images of traced NPY- (in the case of WT mice, $\boldsymbol{K}$ ) and NPY ${ }^{+}$(in the case of Tau ${ }^{\mathrm{VLW}}$ mice, $\boldsymbol{L}$ ) DGIs. $\boldsymbol{M}-\boldsymbol{N}$ : Percentage of traced cells located in different brain regions in WT $(\boldsymbol{M})$ and Tau ${ }^{\mathrm{vLW}}(\boldsymbol{N})$ mice. In $\boldsymbol{B}-\boldsymbol{D}$ and $\boldsymbol{G}, \boldsymbol{H}, \boldsymbol{M}$, and $\boldsymbol{N}, n=5$ female mice per genotype. Asterisks indicate changes with respect to WT animals. H, Hilus; GCL, granule cell layer; DG, dentate gyrus. Yellow scale bar, $50 \mu \mathrm{m}$; pink scale bar, $200 \mu \mathrm{m}$. white scale bar, 200 microns Blue triangles indicate single transduced starter cells $\left(\mathrm{GFP}^{+} \mathrm{mCherry}^{-}\right)$; green triangles, double transduced starter cells $\left(\mathrm{GFP}^{+} \mathrm{mCherry}{ }^{+}\right)$; white triangles, traced cells. ${ }^{*} 0.05>p \geq 0.01 ;{ }^{* * *} 0.001>p$. 
A
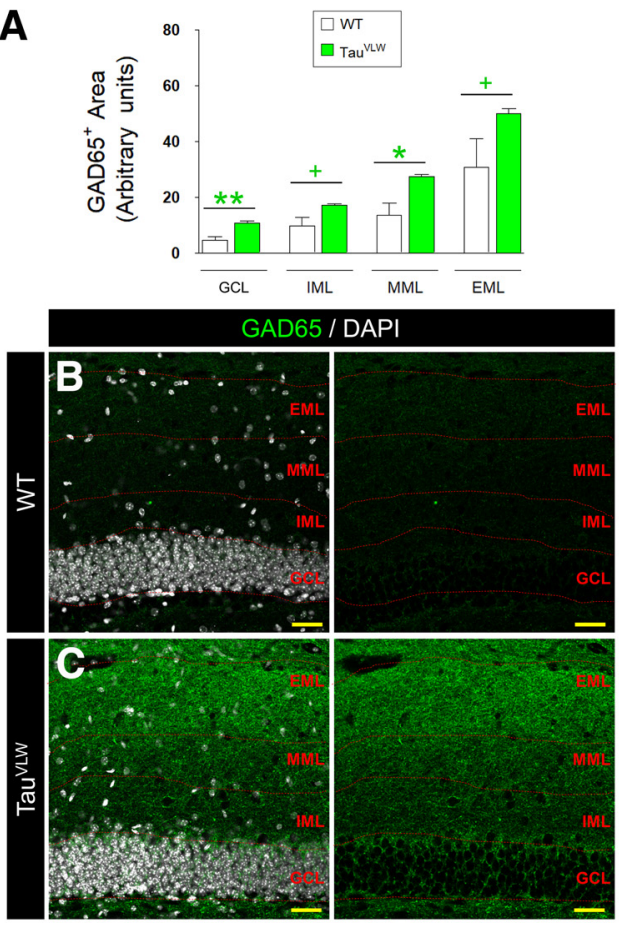

G
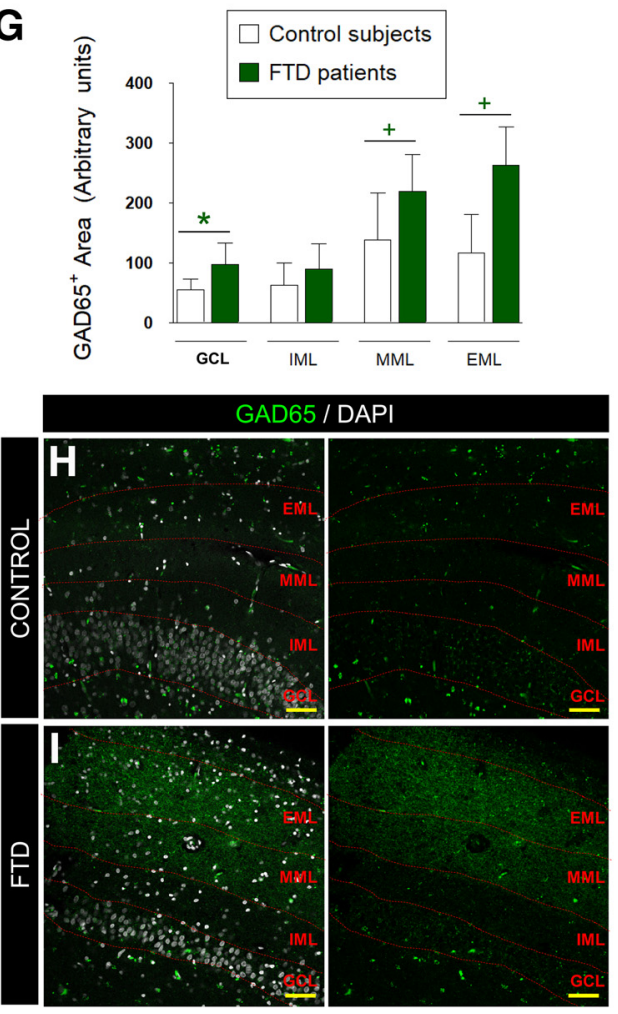
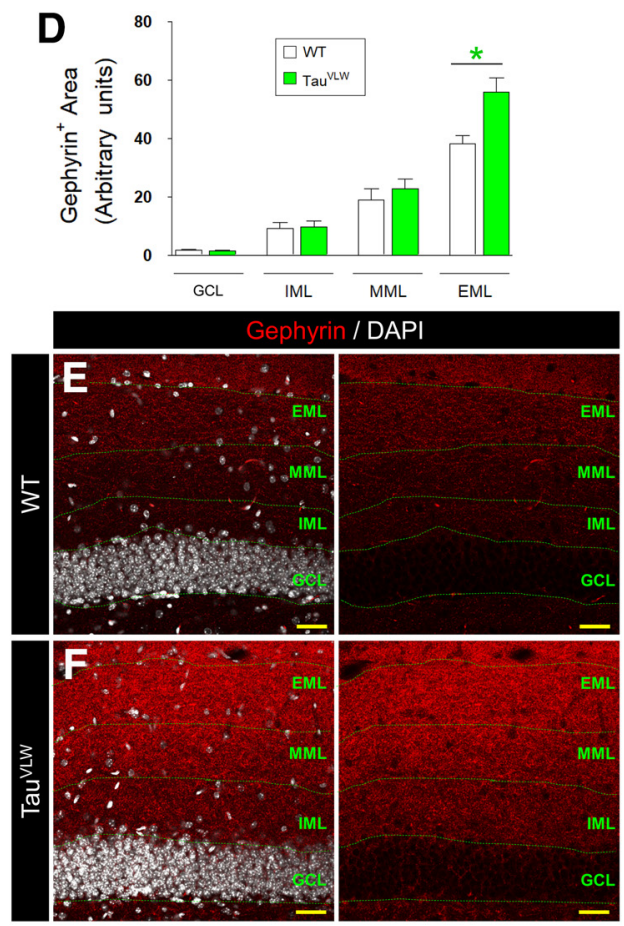

$\mathbf{J}$
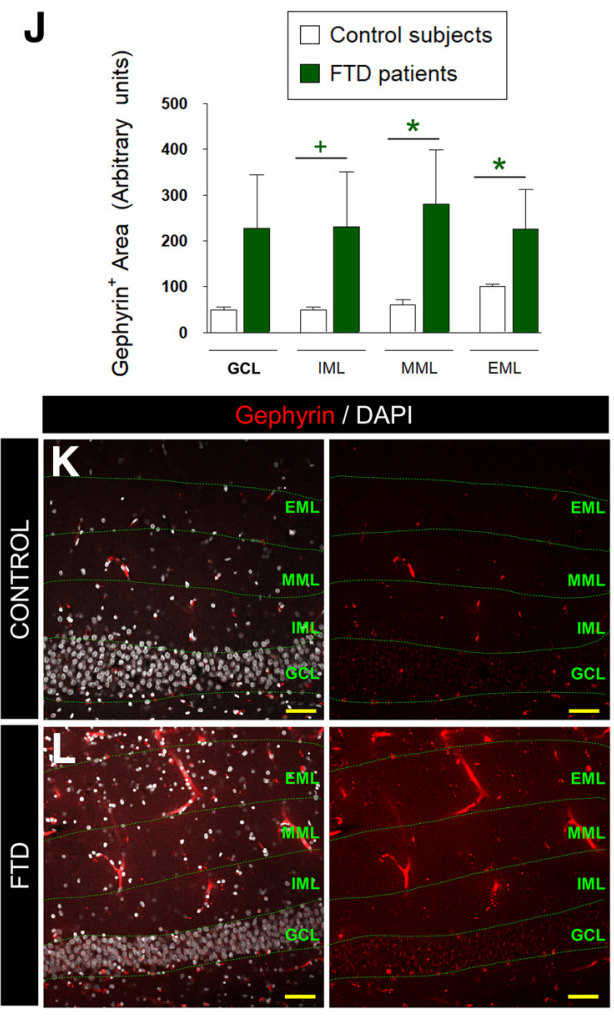

Figure 6. Increased expression of markers of inhibitory synapses in the DG of Tau ${ }^{\mathrm{VLW}}$ mice and patients with FTD. $\boldsymbol{A}-\boldsymbol{C}$, Analysis of the expression of the inhibitory synapse presynaptic marker GAD65 in the DG of WT and Tau ${ }^{\mathrm{VLW}}$ mice. $\boldsymbol{A}, \mathrm{GAD}^{+}{ }^{+}$area in different subregions of the DG in WT and Tau ${ }^{\mathrm{VLW}}$ mice. In $\boldsymbol{B}$ and $\boldsymbol{C}$, representative images of GAD65 staining in WT (B) and Tau ${ }^{\mathrm{VLW}}(\boldsymbol{C})$ mice are shown. $\boldsymbol{D}-\boldsymbol{F}$, Analysis of the inhibitory synapse postsynaptic marker Gephyrin in the DG of WT and Tau ${ }^{\text {vLw }}$ mice. $\boldsymbol{D}$, Gephyrin ${ }^{+}$area in different subregions of the DG. In $\boldsymbol{E}$ and $\boldsymbol{F}$, representative images of Gephyrin staining in $W T(E)$ and $\operatorname{Tau}^{\mathrm{VLW}}(\boldsymbol{F})$ mice are shown. In $\boldsymbol{A}$ and $\boldsymbol{D}, n=104$-month-old female mice per genotype. Five stacks of images per animal were analyzed. Asterisks indicate changes with respect to WT animals. G-I, Analysis of the expression of the inhibitory synapse presynaptic marker GAD65 in the DG of control subjects and FTD patients. G, GAD65 ${ }^{+}$ area in different subregions of the DG in control subjects and FTD patients. In $\boldsymbol{H}$ and $\boldsymbol{I}$, representative images of GAD65 staining in control subjects $(\boldsymbol{H})$ and FTD patients $(\boldsymbol{I})$ are shown. $\boldsymbol{J}-\boldsymbol{L}$, Analysis of the inhibitory synapse postsynaptic marker Gephyrin in the DG of control subjects and FTD patients. $J$, Gephyrin ${ }^{+}$area in different subregions of the DG in control subjects and FTD patients. In $\boldsymbol{K}$ and $\boldsymbol{L}$, representative images of Gephyrin staining in control subjects $(\boldsymbol{K})$ and FTD patients $(\boldsymbol{L})$ are shown. In $\boldsymbol{G}$ and $\boldsymbol{J}, n=5$ control subjects and $n=3$ FTD patients. Five stacks of images per subject were analyzed. Asterisks indicate changes with respect to control subjects. GCL, granule cell layer; EML, External molecular layer; MML, Medial molecular layer, IML, Inner molecular layer. Yellow scale bar, $50 \mu \mathrm{m} .{ }^{+} 0.1>p \geq 0.05 ;{ }^{*} 0.05>p \geq 0.01 ;{ }^{* *} 0.01>p>0.001$. 

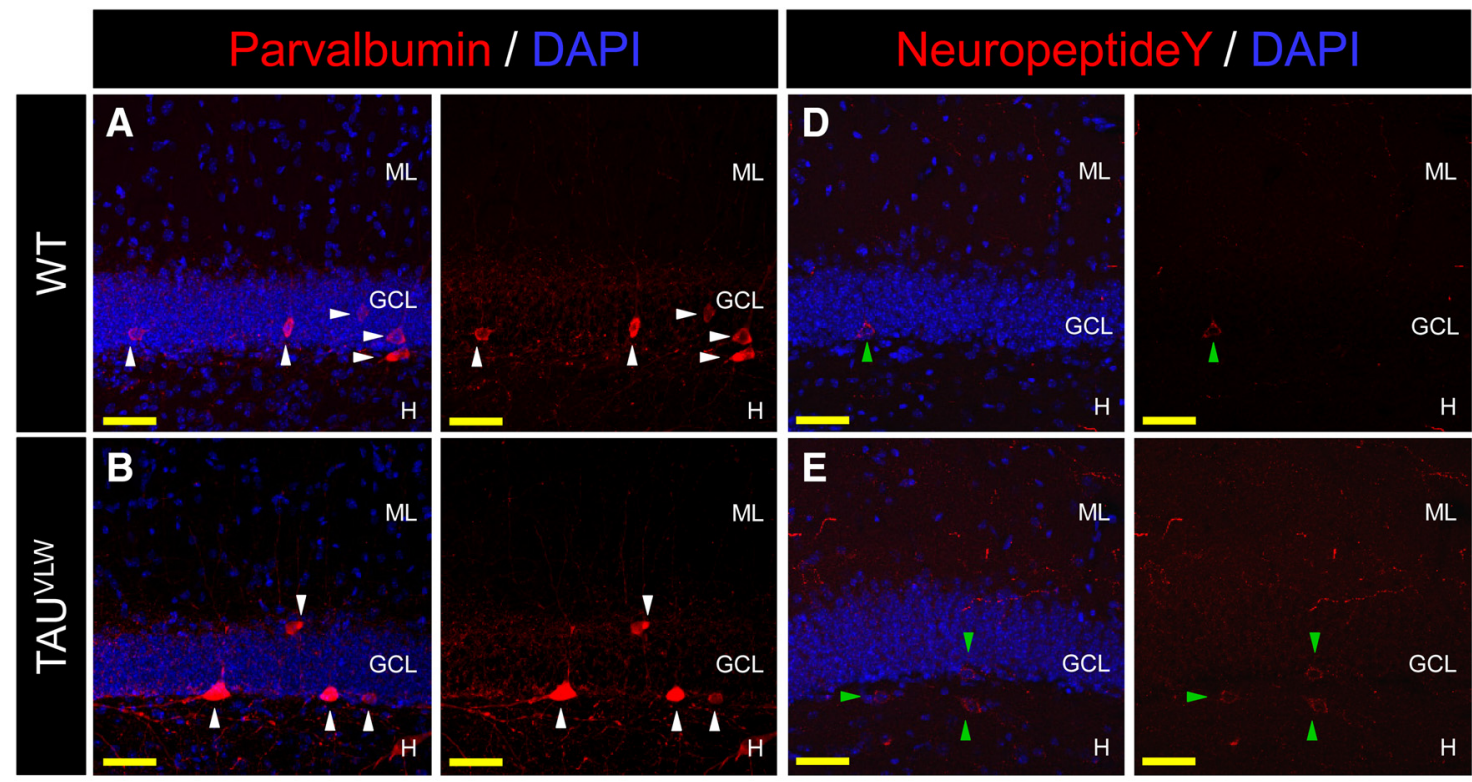

C

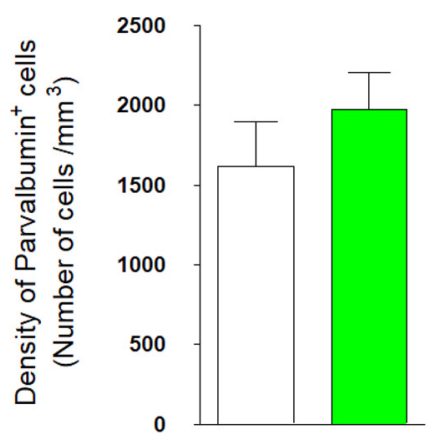

$\mathbf{F}$

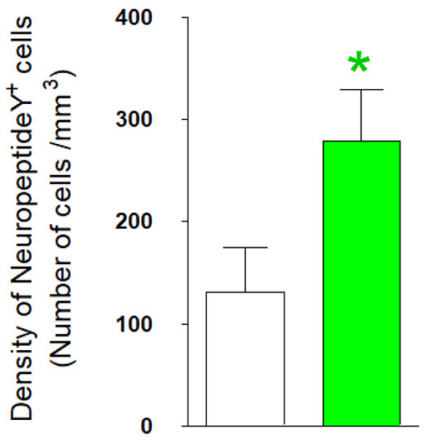

Figure 7. Alteration of the number of $\mathrm{PV}^{+}$and $\mathrm{NPY}^{+}$interneurons in the DG of Tau ${ }^{\mathrm{VLW}}$ mice. $\boldsymbol{A}, \boldsymbol{B}$, Representative images of $\mathrm{PV}^{+}$interneurons in the DG of WT $(\boldsymbol{A})$ and Tau $\mathrm{VLW}(\boldsymbol{B})$ mice. $\boldsymbol{C}$, Number of $\mathrm{PV}^{+}$interneurons in the GCL. $\boldsymbol{D}, \boldsymbol{E}$, Representative images of $\mathrm{NPY}^{+}$interneurons in the DG of WT $(\boldsymbol{D})$ and Tau ${ }^{\mathrm{VLW}}(\boldsymbol{E})$ mice. $\boldsymbol{F}$, Number of $\mathrm{NPY}{ }^{+}$interneurons in the GCL. In $\boldsymbol{C}$ and $\boldsymbol{F}, n=$ 104 -month-old female mice per genotype. Five stacks of images per animal and type of interneuron were analyzed. Asterisks indicate changes with respect to WT animals. GCL, granule cell layer; $\mathrm{ML}$, Molecular layer; $\mathrm{H}$, Hilus. Yellow scale bar, $50 \mu \mathrm{m}$; white triangles, $\mathrm{PV}^{+}$interneurons; green triangles, $\mathrm{NPY}^{+}$interneurons. ${ }^{*} 0.05>p \geq 0.01$.

tions in Tau ${ }^{\mathrm{VLW}}$ newborn DGCs (Fig. 11). To selectively induce the chemoactivation of these cells, clozapine- $N$-oxide $(\mathrm{CNO})$ and a retrovirus that encodes green fluorescent protein (GFP) and the activator hM3D DREADD were used (Alexander et al., 2009; Temprana et al., 2015; Alvarez et al., 2016). We used five female mice per genotype and experimental condition. Animals were 7 weeks old at the time of stereotaxic injections.

\section{Human subjects}

A total of eight individuals (five control subjects and three FTD patients) were included in the study. Figure 2 shows detailed epidemiological data of these subjects. The use of brain tissue samples was coordinated by the local Brain Bank (Banco de Tejidos CIEN, Madrid, Spain), following national laws and international ethical and technical guidelines on the use of human samples for biomedical research purposes (Martínez-Martín and Avila, 2010). Samples were collected at the Banco de Tejidos CIEN (Madrid, Spain), Hospital Clínico Universitario Virgen de la Arrixaca (Murcia, Spain), and Biobanco del Hospital Universitario Reina Sofia (Córdoba, Spain). In all cases, brain tissue donation, processing, and use for research were in compliance with published protocols (International Society for Biological and Environmental Repositories (2012)), which include the obtain- ing of informed consent for brain tissue donation from living donors, and the approval of the whole donation process by the Ethical Committee of the Banco de Tejidos CIEN (Committee Approval Reference \#15-20130110\#). To determine Braak-Tau stage, Tau phosphorylation (AT100 epitope) in the anterior hippocampus; prefrontal, parietal, and temporal associative isocortex; and primary visual cortex was quantified at the Neuropathology Unit of the Banco de Tejidos CIEN following previously described protocols (Braak and Braak, 1995; Braak et al., 2006).

\section{Human hippocampal dissection and fixation}

Immediately after brain extraction, the posterior poles of both the mammillary bodies and the uncus (Mai and Paxinos, 2015) were identified. Next, a coronal 1-cm-thick slice of the whole hemisphere was obtained at this anatomical level. After identification of the aforementioned anatomical references, a 1-cm-thick hippocampal sample corresponding to the posterior portion of the anterior hippocampus was rapidly dissected on ice. This sample was then rostrocaudally divided into two halves. The anterior half was rapidly immersed in Golgi solution and the posterior half was immediately immersed in freshly prepared $4 \%$ paraformaldehyde, $\mathrm{pH} 7.4$, for $24 \mathrm{~h}$. 

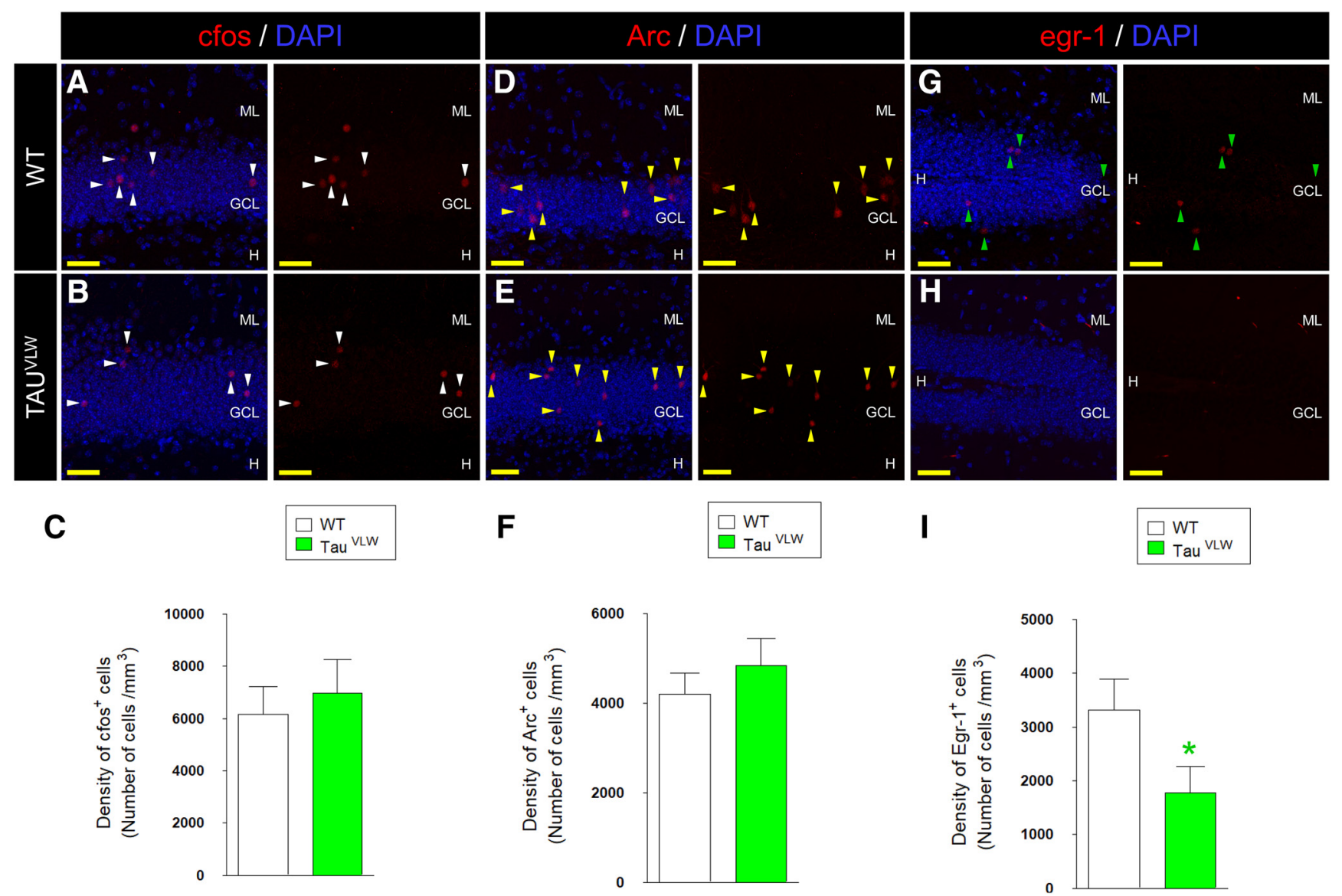

Figure 8. Expression of cfos ${ }^{+}$, Arc ${ }^{+}$and egr- $1^{+}$cells in DGCs of Tau ${ }^{\mathrm{VLW}}$ mice. $\boldsymbol{A}, \boldsymbol{B}$, Representative images of cfos ${ }^{+}$cells in the DG of WT $(\boldsymbol{A})$ and Tau ${ }^{\text {VLW }}(\boldsymbol{B})$ mice. $\boldsymbol{C}$, Number of cfos $^{+}$cells in the GCL. D, $\boldsymbol{E}$, Representative images of Arc ${ }^{+}$cells in the DG of WT (D) and Tau ${ }^{\mathrm{VLW}}(\boldsymbol{E})$ mice. $\boldsymbol{F}$, Number of Arc ${ }^{+}$cells in the GCL. $\boldsymbol{G}, \boldsymbol{H}$, Representative images of egr- $1^{+}$cells in the DG of WT (G) and $\operatorname{Tau}^{\operatorname{VLW}}(\boldsymbol{H})$ mice. $\boldsymbol{I}$, Number of egr- ${ }^{+}$cells in the GCL. In $\boldsymbol{C}, \boldsymbol{F}$, and $\boldsymbol{I}, n=10$ female mice per genotype. All animals were $7-8$ weeks old at the beginning of these experiments. Five stacks of images per animal and cell marker were analyzed. Asterisks indicate changes with respect to WT animals. GCL, granule cell layer; ML, Molecular layer; H, Hilus. Yellow scale bar, $50 \mu \mathrm{m}$; white triangles, fos ${ }^{+}$ cells; yellow triangles, Arc ${ }^{+}$cells; green triangles, egr- ${ }^{+}{ }^{+}$cells. ${ }^{*} 0.05>p \geq 0.01$.

\section{Human hippocampal tissue sectioning}

To increase tissue robustness and to prevent tissue damage during sectioning, fixed hippocampal blocks were included in a $10 \%$ sucrose $-4 \%$ agarose solution. Blocks were cut on a Leica VT-1200S sliding blade vibratome (speed: $1-1.3$; amplitude: 1.9 ), obtaining $50-\mu$ m-thick sections. After vibratome sectioning, brain sections were immediately stored at $-20^{\circ} \mathrm{C}$ in a cryopreservative solution ( $30 \%$ polyethylene glycol; $10 \% 0.2$ N PB; $30 \%$ glycerol; $30 \%$ double-distilled water).

\section{Golgi staining}

Either a fresh fragment of human hippocampus containing the DG or the whole brain in the case of mouse experiment was dissected and immersed in Golgi-Cox staining solution (FD Neurotechnologies, FD Rapid GolgiStain kit). Human samples were incubated in this solution for $14 \mathrm{~d}$ and murine samples were incubated for $28 \mathrm{~d}$, all samples being protected from light. Next, $150 \mu \mathrm{m}$ sections were obtained in a Leica VT1200S vibratome and mounted on gelatin-coated slides. After Golgi staining, all sections were counterstained with toluidine blue (Llorens-Martín et al., 2006). The dendritic trees of DGCs were examined under an inverted Axiovert200 Zeiss optical microscope ( $40 \times$ dry objective) coupled to a camera lucida (Drakew et al., 1999). Morphometric analyses were performed as described previously (Llorens-Martín et al., 2013).

\section{Animals}

$\mathrm{Tau}^{\mathrm{VLW}}$ mice were generated as described previously (Lim et al., 2001). Briefly, these mice carry three mutations, G272V (V), P301L (L), and R406W (W), on human MAPT, which are related to familial forms of FTD-Tau. The plasmid pSGT42 (Montejo de Garcini et al., 1994), which encodes a human four-repeat Tau cDNA isoform with two N-terminal exons, was used as a template to introduce the mutations by site-directed mutagenesis. Neuron-specific expression was driven by insertion of human Tau cDNA into a murine Thy 1 expression cassette. Tau ${ }^{\mathrm{VLW}}$ and WT littermates were generated and housed in a specific pathogen-free colony facility at the Centro de Biología Molecular "Severo Ochoa" (CBMSO). Given that hierarchy/ dominance relationships between male mice have a negative impact on AHN (Kozorovitskiy and Gould, 2004), only female mice were used in this study. All mice were 7 weeks old at the time of stereotaxic injections. They were housed in accordance with European Community Guidelines (directive 86/609/EEC) and handled following European and local animal care protocols. Four to five mice were housed per cage. For EE experiments, animals were housed in groups of 10 . Animal experiments were approved by the CBMSO Ethics Committee (AEEC-CBMSO-23/172) and the National Ethics Committee (PROEX 205/15).

\section{Preparation of viral stocks}

$R G B$ retroviruses. These viruses were used to analyze the morphology of three cell subpopulations of adult-born DGCs of different ages in the same mice. We used three retroviral stocks encoding for either mCherry (Red, R), Venus (Green, G), or Cerulean (Blue, B) fluorescent proteins on a RSF91 backbone (Schambach et al., 2006; Gomez-Nicola et al., 2014). The plasmids used to produce these viruses were kindly provided by R. Tsien (Howard Hughes Medical Institute Laboratory at the University of California, San Diego), C. Baum and A. Schambach (Hannover Medical School, Germany), A. Miyawaki (RIKEN Brain Science Institute, Saitama, Japan), and C. Riecken (University Medical Center Hamburg-Eppendorf, Germany). 

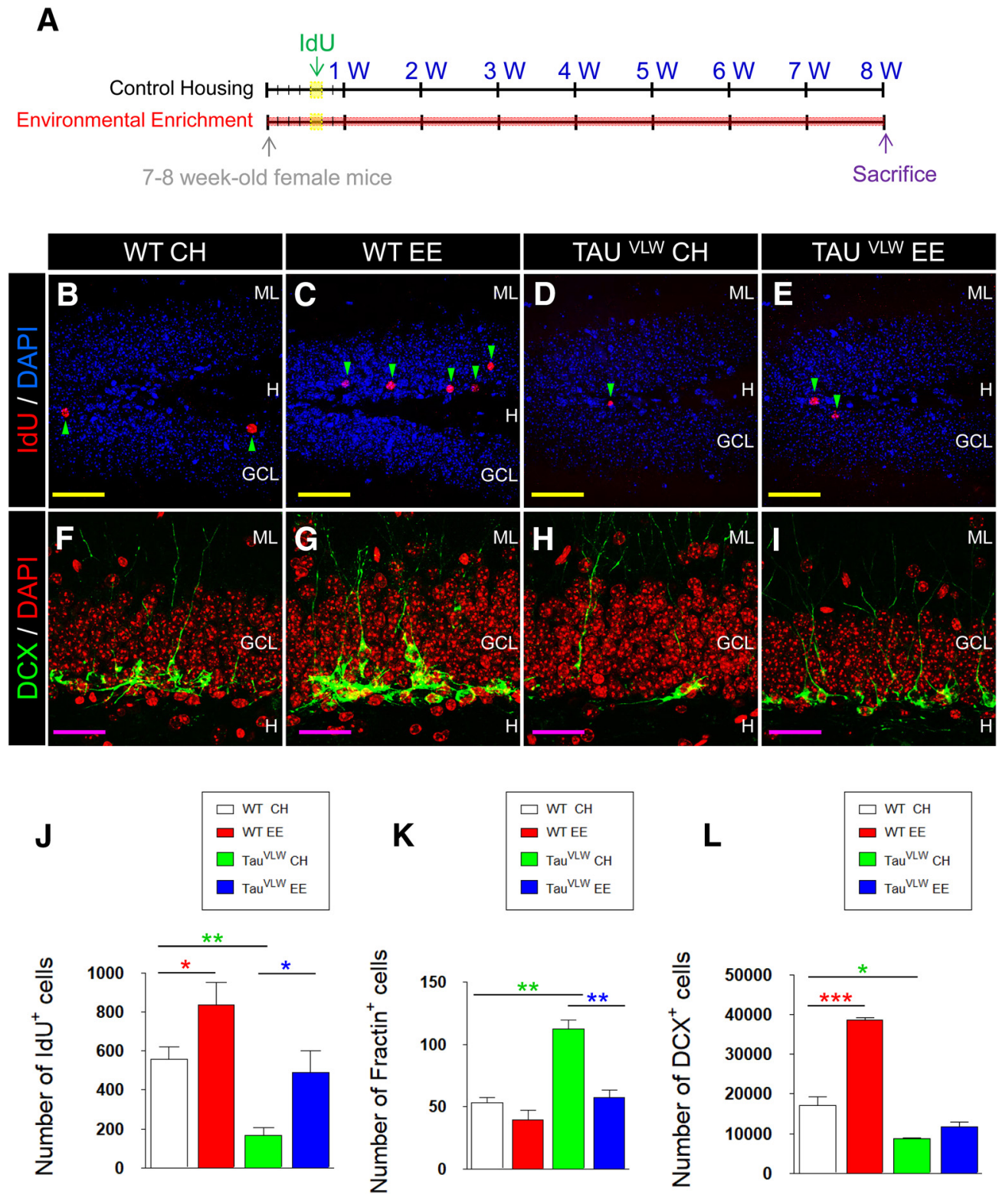

Figure 9. Responsiveness of AHN rate to the stimulatory effects of EE in Tau ${ }^{\mathrm{VLW}}$ mice. $\boldsymbol{A}$, Experimental design and thymidine analog administration schedule. $\boldsymbol{B}-\boldsymbol{I}$, Representative images of IdU $(\boldsymbol{B}-\boldsymbol{E})$ and DCX $(\boldsymbol{F}-\boldsymbol{I})$ staining in the DG. $\boldsymbol{J}$, Number of IdU ${ }^{+}$cells. $\boldsymbol{K}$, Number of Fractin ${ }^{+}$cells. $\boldsymbol{L}$, Number of $D C X^{+}$cells. In $\boldsymbol{J}-\boldsymbol{L}, n=10$ female mice per genotype. All animals were $7-8$ weeks old at the beginning of these experiments. Five stacks of images per animal and cell marker were analyzed. Asterisks indicate changes with respect to WT CH animals. GCL, granule cell layer; $\mathrm{ML}$, Molecular layer. H, Hilus. Yellow scale bar, $100 \mu \mathrm{m}$; pink scale bar, $50 \mu \mathrm{m}$. Green triangles, IdU ${ }^{+}$cells. ${ }^{*} 0.05>p \geq 0.01 ;{ }^{* *} 0.01>p \geq 0.001 ;{ }^{* * *} 0.001>p$.

PSD95:GFP- and Syn:GFP-encoding retroviruses. We used two retroviral stocks encoding for either PSD95:GFP (Kelsch et al., 2008) or Syn: GFP (Kelsch et al., 2010) (Syn:GFP). A PSD95:GFP-encoding retrovirus was used to analyze the PSDs of adult-born DGCs as a measurement of the afferent connectivity of these cells (Kelsch et al., 2008; Llorens-Martín et al., 2013). A Syn:GFP-encoding retrovirus was used to analyze the active zone of the mossy fiber terminals (MFTs) of adult-born DGCs as a measurement of their efferent connectivity (Kelsch et al., 2010). The plasmids used to produce these viruses were kindly provided by C. Lois (Cal Tech, Pasadena).

$R V$-Syn-GTRgp retrovirus and EnvA- $G$-MCh rabies virus. We used a RV-Syn-GTRgp retrovirus to label a population of adult-born DGC starter cells (Vivar et al., 2012). The plasmid used to produce this virus was kindly provided by FH. Gage (Salk Institute, California). To label the cells that presynaptically innervate starter adult-born DGCs, an EnvA$\Delta \mathrm{G}-\mathrm{MCh}$ rabies virus was used (Vivar et al., 2012). Rabies virus particles were synthesized as described previously (Vivar et al., 2012). The plasmid used to produce this virus was kindly provided by E. Callaway (Salk Institute).

Retroviruses encoding red fluorescent protein (RFP) and hM3D, a human muscarinic receptor M3 Designer receptor exclusively activated by designer drugs (DREADD). To induce the chemoactivation of adult-born DGCs, a retrovirus that encodes GFP and the activator hM3D DREADD was used (Alexander et al., 2009; Temprana et al., 2015; Alvarez et al., 2016). Animals received a stereotaxic injection of two retroviruses (1:1 ratio) that encoded either hM3D or RFP (Alvarez et al., 2016). The plasmid used to produce the hM3D-encoding retrovirus was kindly provided by B. Roth (University of North Carolina at Chapel Hill). The plasmids used to produce the RFP-encoding retrovirus were kindly provided by F. Calegari (Center for Regenerative Therapies Dresden, Dresden, Germany) and FH. Gage (Salk Institute).

The plasmids used to package all retroviral particles were kindly provided by FH. Gage (Salk Institute). Retroviral stocks were concentrated to working titers of $1 \times 10^{7}$ to $2 \times 10^{8} \mathrm{pfu} / \mathrm{ml}$ by ultracentrifugation 
A

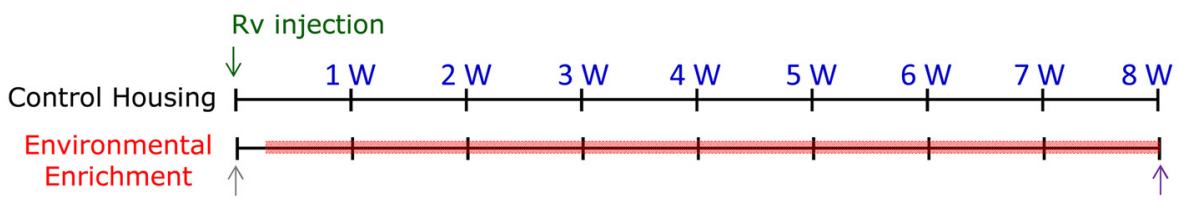

7 week-old female mice
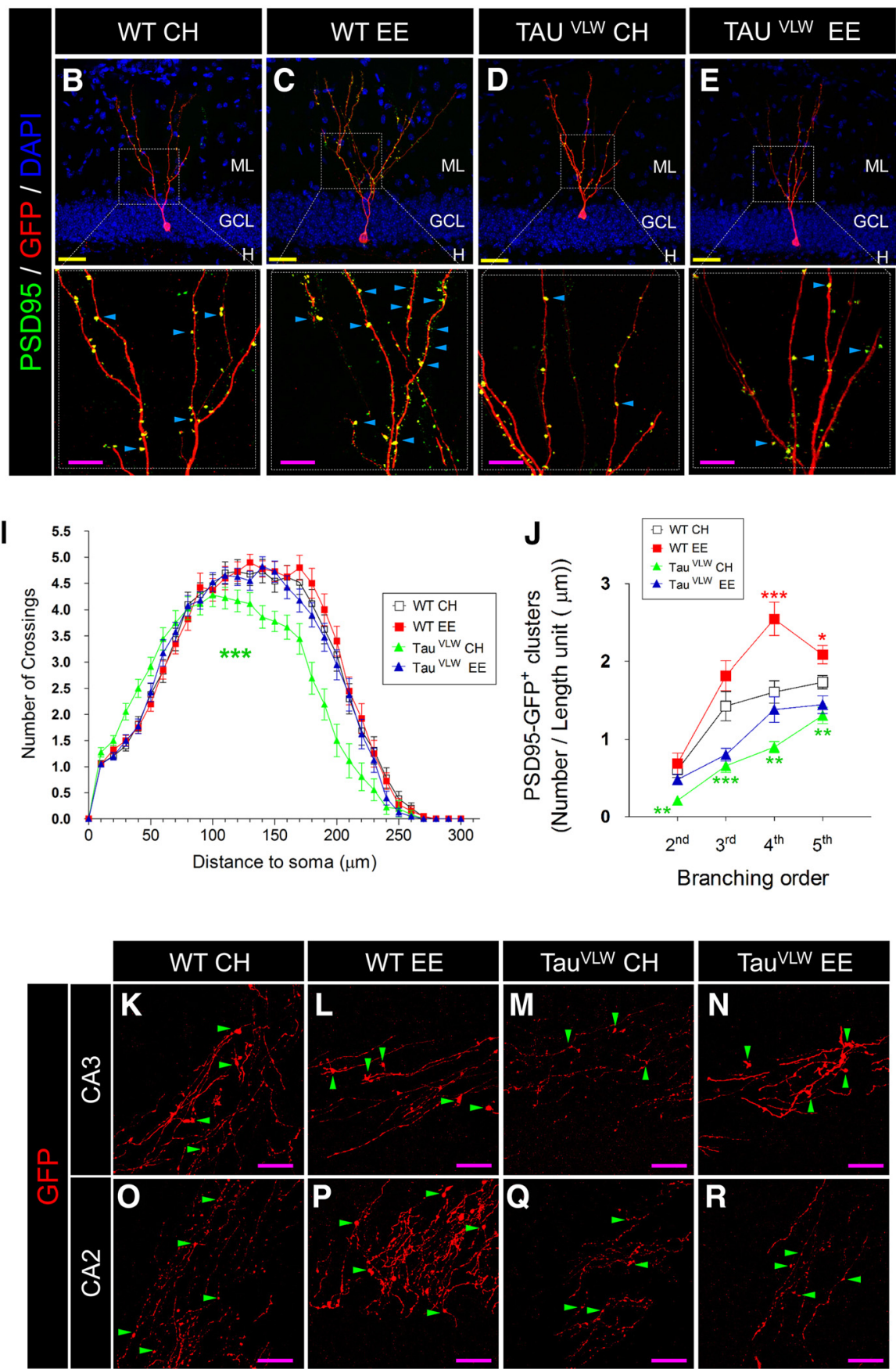

$\mathbf{F}$
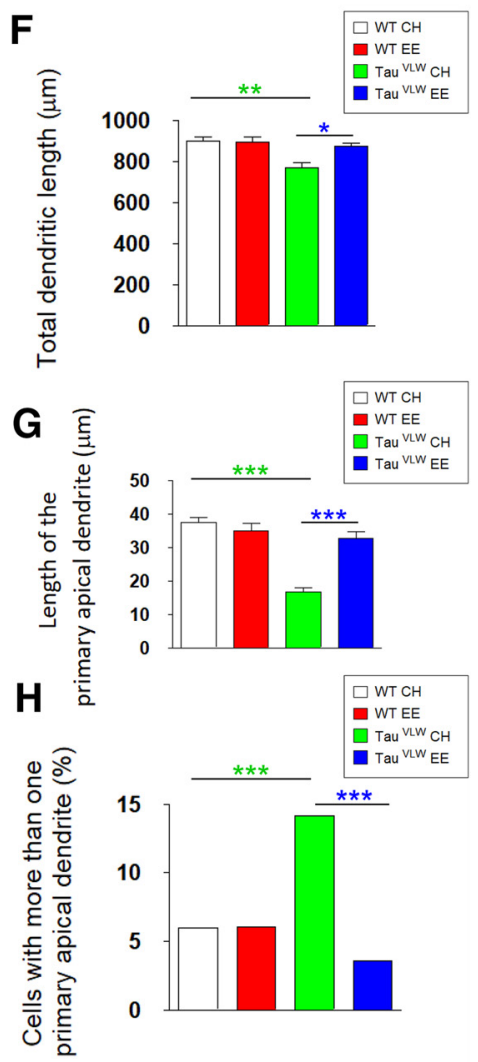

S
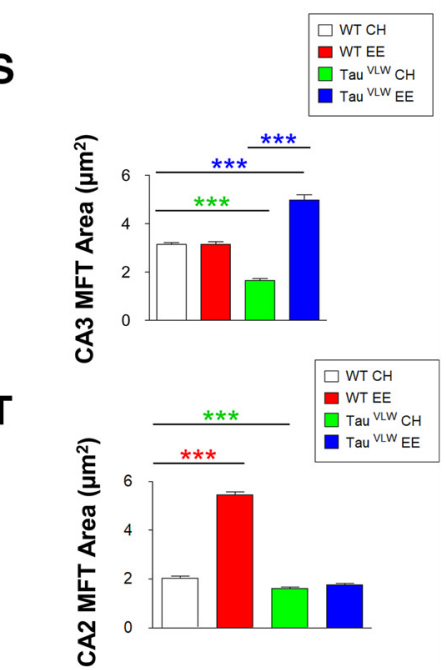

Figure 10. Effects of EE on the morphological and functional maturation of newborn DGCs in Tau ${ }^{\text {VLW }}$ mice. $A$, Experimental design. Briefly, a PSD95:GFP-encoding retrovirus was stereotaxically injected into the hippocampus of WT and Tau ${ }^{\text {VLW }}$ mice. Animals were assigned to either control housing (CH) or EE conditions and killed 8 weeks later. B-E, Representative images of PSD95:GFPtransduced cells and their respective high-power magnification images showing the presence of PSDs. $\boldsymbol{F}$, Total dendritic length. $\boldsymbol{G}$, Length of the primary apical dendrite. $\boldsymbol{H}$, Percentage of cells with several primary apical dendrites. $I$, Sholl's analysis. In $\boldsymbol{F}-\boldsymbol{I}$, at least 50 cells per experimental condition and genotype were analyzed. J, Density of PSDs along the whole dendritic tree. In $J$, at least 50 dendritic fragments per branching order, experimental condition and genotype were analyzed. Asterisks indicate changes with respect to WT $\mathrm{CH}$ animals. $\boldsymbol{K}$ - $\boldsymbol{R}$ : Representative high-power magnification images of MFTs in the CA3 $(\boldsymbol{K}-\boldsymbol{N})$ and the CA2 $(\boldsymbol{O}-\boldsymbol{R})$ regions. S, Quantification of the area of individual MFTs in the CA3 field. $\boldsymbol{T}$, Quantification of the area of individual MFTs in the $C A 2$ field. In $\boldsymbol{S}$ and $\boldsymbol{T}$, a minimum of 20 stacks of images per animal and region were obtained. A minimum of $400 \mathrm{MFT}$ s per region, experimental condition and genotype were analyzed. In $\boldsymbol{F}-\boldsymbol{J}, \boldsymbol{S}$, and $\boldsymbol{T}$, $n=5$ female mice per genotype. All animals were 7 weeks old at the beginning of these experiments. GCL, granule cell layer; ML, Molecular layer. H, Hilus. Yellow scale bar, $50 \mu \mathrm{m}$; pink scale bar, $10 \mu \mathrm{m}$. Blue triangles indicate PSDs; green triangles, MFTs. ${ }^{*} 0.05>p \geq 0.01 ;{ }^{* *} 0.01>p \geq 0.001 ;{ }^{* * *} 0.001>p$. 
A

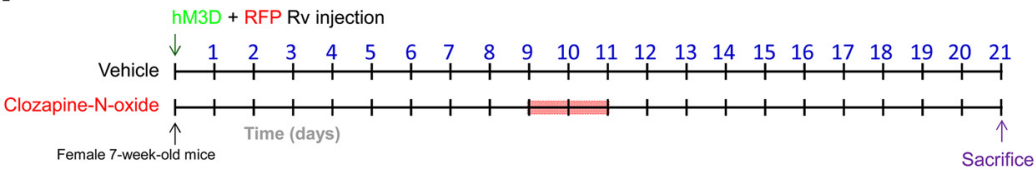

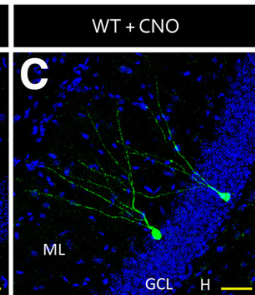
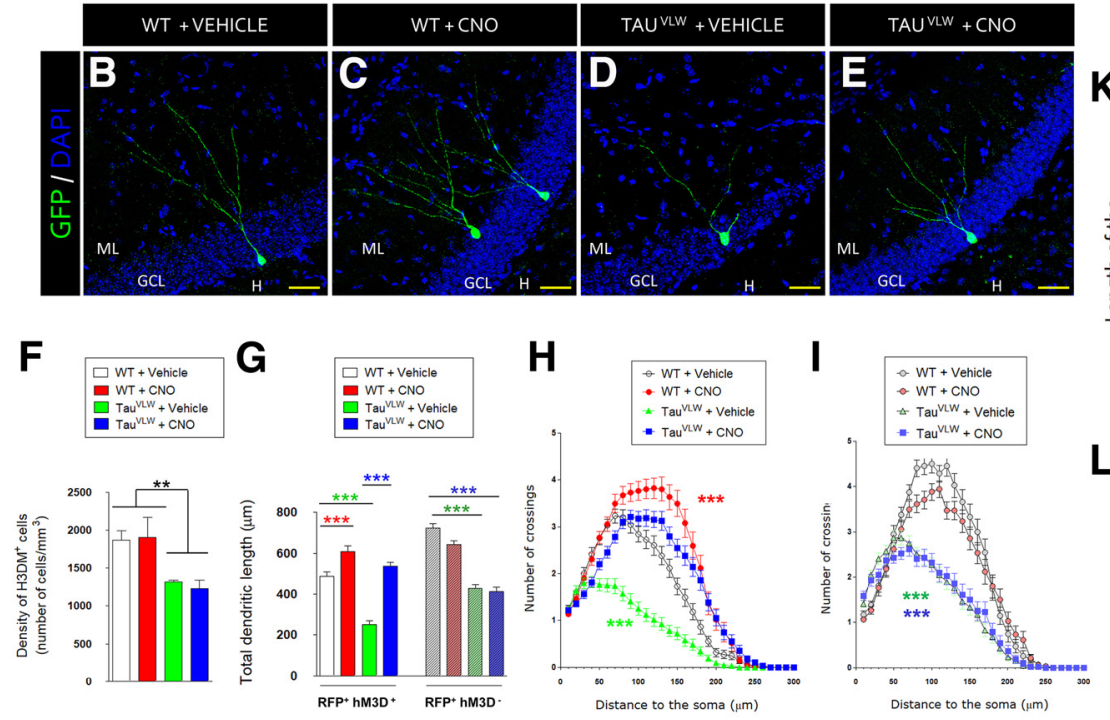
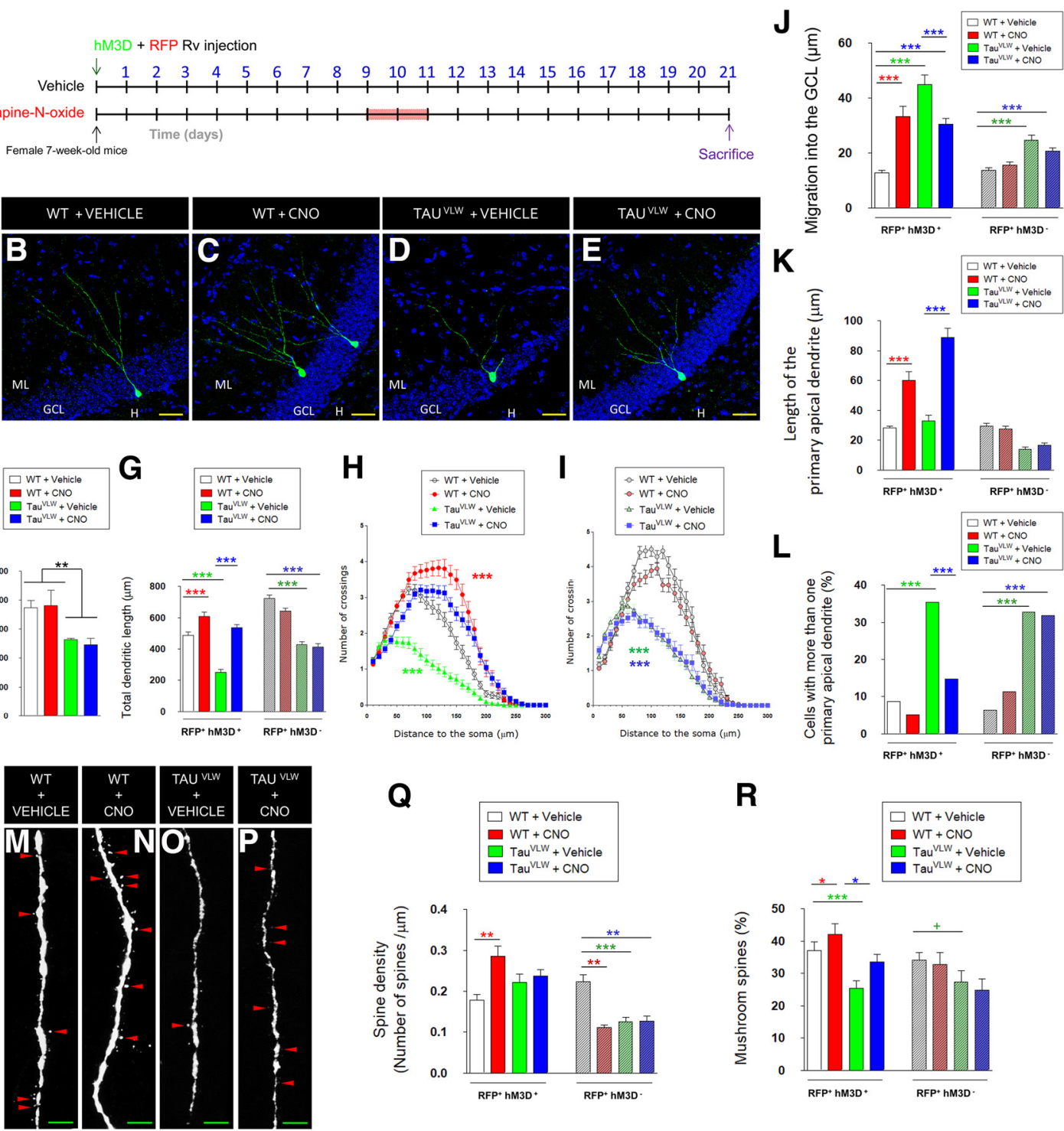

Q
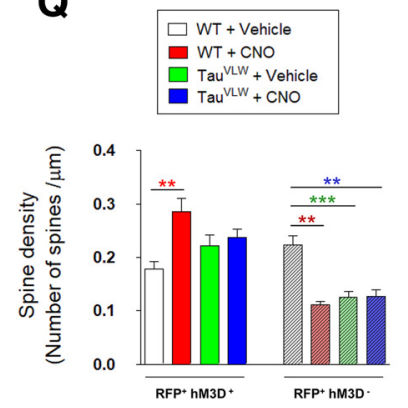

R
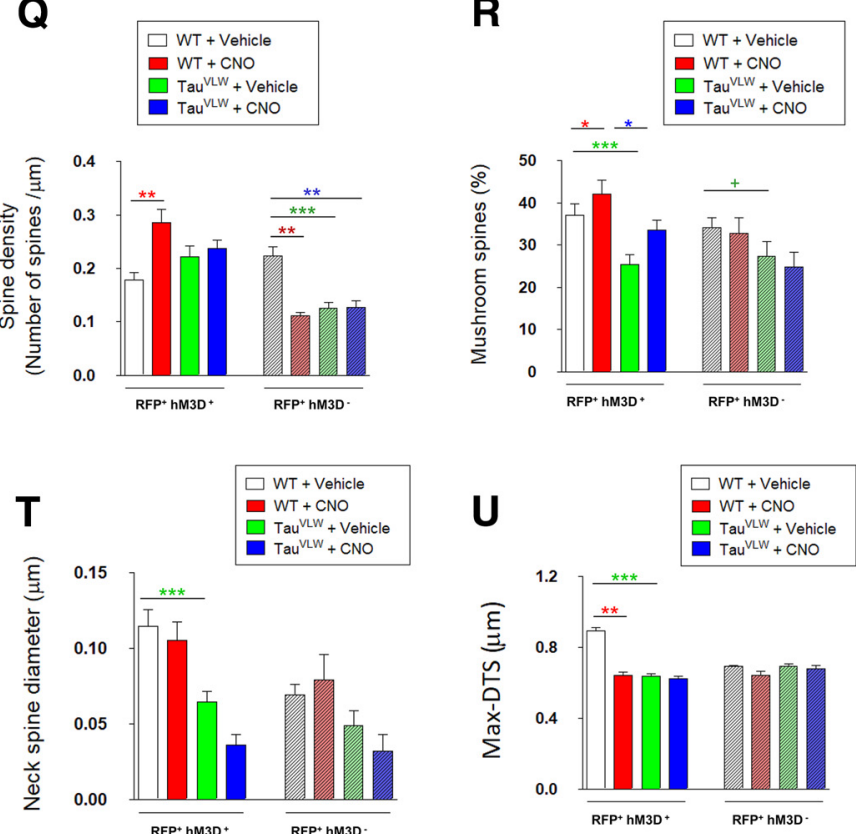

Figure 11. Effects of chemoactivation on the morphology and connectivity of newborn DGCs in Tau ${ }^{\text {VLW }}$ mice. A, Experimental design. Briefly, hM3D:GFP DREADD- and RFP-encoding retroviruses were stereotaxically injected into the hippocampus of WT and Tau ${ }^{\mathrm{VLW}}$ mice. Half of the animals received CNO in drinking water for 2 consecutive days during the so-called critical period of adult-born DGCS. CNO causes chemoactivation of the population of adult-born DGCs transduced by the hM3D-encoding retrovirus. $\boldsymbol{B}$ - $\boldsymbol{E}$, Representative images of hM3D:GFP-transduced cells. $\boldsymbol{F}$, Effects of

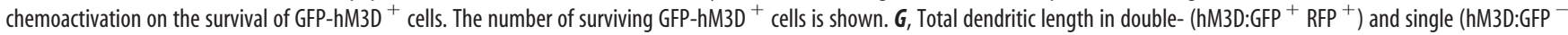
$\mathrm{RFP}^{+}$)-transduced cells. $\boldsymbol{H}$, Sholl's analysis of double- (hM3D:GFP ${ }^{+}$RFP $^{+}$)-transduced cells. $\boldsymbol{I}$, Sholl's analysis of single (hM3D:GFP ${ }^{-}$RFP ${ }^{+}$)-transduced cells. J, Migration into the GCL of double-

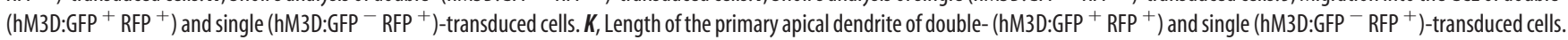

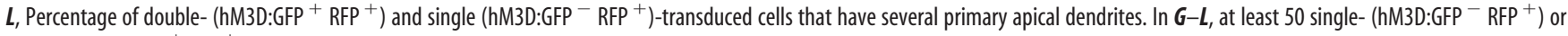
double- (hM3D:GFP ${ }^{+}$RFP $^{+}$)-transduced cells per experimental condition and genotype were analyzed. $\boldsymbol{M}-\boldsymbol{P}$, High-power magnification images of double transduced cells showing the presence of dendritic spines. Q, Density of dendritic spines in double- (hM3D:GFP ${ }^{+}$RFP ${ }^{+}$) and single (hM3D:GFP ${ }^{-}$RFP ${ }^{+}$)-transduced cells. $\boldsymbol{R}$, Percentage of mushroom spines in double- (hM3D:GFP ${ }^{+}$

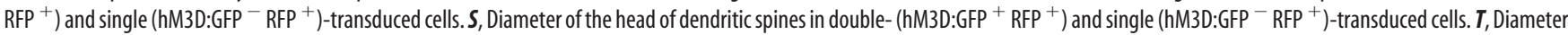
of the neck of dendritic spines in double- (hM3D:GFP ${ }^{+}$RFP $^{+}$) and single (hM3D:GFP ${ }^{-}$RFP ${ }^{+}$)-transduced cells. $\boldsymbol{U}$, Length of dendritic spines (Max-DTS) in double- (hM3D:GFP ${ }^{+}$RFP $^{+}$) and single (hM3D:GFP ${ }^{-}$RFP $^{+}$)-transduced cells. In Q-U, At least 50 dendritic fragments of either single- (hM3D:GFP ${ }^{-}$RFP $^{+}$) or double (hM3D:GFP ${ }^{+}$RFP $^{+}$)-transduced cells per experimental condition and genotype were analyzed. In $\boldsymbol{F}-\boldsymbol{L}$, and $\mathbf{Q}-\boldsymbol{U}, n=5$ female mice per genotype All animals were 7 weeks old at the beginning of these experiments. $\mathrm{GCL}$, granule cell layer; $\mathrm{ML}$, Molecular layer; $\mathrm{H}$, Hilus. Yellow scale bar, $50 \mu \mathrm{m}$; green scale bar, $10 \mu \mathrm{m}$. Red triangles, Mushroom spines. ${ }^{+} 0.1>p \geq 0.05 ;{ }^{*} 0.05>p \geq 0.01 ;{ }^{* *} 0.01>p \geq 0.001 ;{ }^{* * *} 0.001>p$. 
(Zhao et al., 2006). Because the retroviruses used are engineered to be replication incompetent, only cells dividing at the time of surgery are infected (Zhao et al., 2006). In the DG, these proliferative cells are almost totally restricted to adult-born DGCs (Zhao et al., 2006).

\section{Stereotaxic surgery}

Seven-week-old mice were anesthetized with isoflurane and placed in a stereotaxic frame. Viruses were injected into the DG at the following coordinates (in $\mathrm{mm}$ ) relative to bregma in the anteroposterior, mediolateral, and dorsoventral axes: $[-2.0, \pm 1.4,2.2]$. Next, $2 \mu$ lof virus was infused at a rate of $0.2 \mu \mathrm{l} / \mathrm{min}$ via a glass micropipette. To avoid any suction effect of the solution injected, micropipettes were kept in place at the site of injection for an additional $5 \mathrm{~min}$ before being slowly removed.

\section{EE}

We used a previously described EE protocol (Llorens-Martín et al., 2010). Twenty-four hours after retroviral injections, mice assigned to EE were housed in large, transparent polycarbonate cages $(55 \times 33 \times 20 \mathrm{~cm}$, Plexx, 13005) for 8 weeks. All enriched cages were equipped with various types of running wheels. The mice had free access to 10 toys that differed in shape, size, material, and surface texture. To alter the environment, a set of 10 different toys and new bedding were placed in the cages every other day (Llorens-Martín et al., 2010). Given that EE cages were placed in nonventilated racks, the mice subjected to control housing $(\mathrm{CH})$ in $\mathrm{EE}$ experiments were housed in nonventilated standard cages for the same period of time.

\section{Administration of thymidine analogs}

The thymidine analog 5-iodo-2'-deoxyuridine (IdU) (Sigma-Aldrich) was used to study the survival of 8-week-old newborn DGCs in animals subjected to EE. IdU was diluted in drinking water at $0.92 \mathrm{mg} / \mathrm{ml}$ and administered over $24 \mathrm{~h}$ on day 5 of the EE protocol. This dose was based on equimolar doses of $50 \mathrm{mg} / \mathrm{kg}$ (Llorens-Martín et al., 2010) and 0.8 $\mathrm{mg} / \mathrm{ml}$ BrdU (Lugert et al., 2010), respectively. The experimental design is shown in Figure $9 A$.

\section{Killing of animals}

Mice were fully anesthetized by an intraperitoneal injection of pentobarbital (EutaLender, $60 \mathrm{mg} / \mathrm{kg}$ ) and transcardially perfused with $0.9 \% \mathrm{sa}-$ line followed by $4 \%$ paraformaldehyde in $0.1 \mathrm{~N}$ phosphate buffer $(\mathrm{PB})$. Brains were removed and postfixed overnight in the same fixative at $4^{\circ} \mathrm{C}$. They were then washed three times in $0.1 \mathrm{~N}$ PB.

\section{Immunohistochemistry (IHC)}

For IHC determinations, $50-\mu \mathrm{m}$-thick sections were obtained on a Leica VT1200S vibratome. Coronal sections were obtained, except in the case of rabies virus experiments, in which horizontal brain sections were used (Vivar et al., 2012). For immunohistochemical analyses, series of brain slices were randomly made up of one section from every ninth. For each series of sections, sampling probability was $1 / 8$. Slices were initially preincubated in PB with 1\% Triton X-100 and 1\% bovine serum albumin. Dual or triple immunohistochemistry was then performed as described previously (Llorens-Martín et al., 2013) using the following primary antibodies: rabbit anti-GFP (Thermo Fisher Scientific, catalog \#A-11122, RRID:AB_221569; 1:1000); rat anti-mCherry (Thermo Fisher Scientific, catalog \#M11217, RRID:AB_2536611; 1:2500); mouse anti-IdU (BD Biosciences, catalog \#347580, RRID:AB_10015219; 1:500); rabbit antiFractin (Acris Antibodies, catalog \#AP08647SU-N, RRID:AB_1975531; 1:500); goat anti-Doublecortin (DCX) (Santa Cruz Biotechnology, catalog \#sc-8066, RRID:AB_2088494; 1:500); mouse anti glutamic acid decarboxylase 65 (GAD65) (Developmental Hybridoma Bank, catalog \#GAD-6, RRID:AB_2314498; 1:500); mouse anti-Gephyrin (Synaptic Systems, catalog \#147 111, RRID:AB_887719; 1:500); rabbit antiphospho-Tau (AT180: Thr231; 1:100) (Thermo Fisher Scientific, catalog \#MN1040, RRID:AB_223649; 1:100); and rabbit anti-phospho-Tau (AT100: Thr212, Ser214; 1:100) (Thermo Fisher Scientific, catalog \#MN1060, RRID:AB_223652; 1:100); guinea pig anti-cfos (Synaptic Systems, catalog \#226003, RRID:AB_2231974; 1:500); rabbit-anti Arc (Synaptic Systems, catalog \#156003, RRID:AB_887694; 1:1000); rat anti egr-1 (R\&D Systems, catalog \#MAB2818, RRID:AB_2097028; 1:100); mouse
anti-PV (Synaptic Systems, catalog \#19-5011, RRID:AB_2619882; 1:500); and guinea pig anti-NPY (Synaptic Systems, catalog \#394004, RRID:AB_2721083; 1:500). To detect the binding of primary antibodies, Alexa Fluor-594 donkey anti-mouse (Invitrogen, catalog \#A-21203, RRID:AB_141633; 1:1000), Alexa Fluor-555 donkey anti-rabbit (Invitrogen, catalog \#A-31572, RRID:AB_162543; 1:1000), Alexa Fluor488 donkey anti-rabbit (Invitrogen, catalog \#A-21206, RRID: AB_141708; 1:1000), Alexa Fluor-555 donkey anti-goat (Invitrogen, catalog \#A-21432, RRID:AB_141788; 1:1000), Alexa Fluor-555 donkey anti-rat (Invitrogen, catalog \#A-21434, RRID:AB_141733; 1:1000), and Alexa Fluor-555 goat anti-guinea pig (Invitrogen, catalog \#A-21435, RRID:AB_2535856; 1:1000) secondary antibodies were used. All sections were counterstained for $10 \mathrm{~min}$ with DAPI (Merck, 1:5000) to label nuclei. IHC in human samples was followed by an autofluorescence elimination step. Briefly, autofluorescence eliminator solution (EMD Millipore; , catalog \#2160) was used following the manufacturer's instructions (Bolós et al., 2017b).

\section{Cell counts}

The number of $\mathrm{IdU}^{+}$, fractin ${ }^{+}, \mathrm{DCX}^{+}, \mathrm{cfos}^{+}, \mathrm{Arc}^{+}$, egr- ${ }^{+}, \mathrm{PV}^{+}$, $\mathrm{NPY}^{+}$, or surviving GFP-hM3D ${ }^{+}$cells in mice, and phopsho-Tau (AT$100)^{+}$DGCs in human patients were counted under a LSM710 Zeiss confocal microscope $(63 \times$ oil-immersion objective) using the physical dissector method adapted for confocal microscopy (Llorens-Martín et al., 2013). Briefly, the reference volume was calculated in Fiji software, as described previously (Bolós et al., 2017b). Next, the number of cells inside the reference volume was determined and then divided by this volume. Data are presented as cell densities (number of cells/cubic millimeter).

\section{Morphometric analysis of three populations of adult-born DGCs in the same mouse}

RGB retroviruses allow the labeling of adult-born DGCs in three colors, red $\left(\mathrm{mCherry}^{+}\right)$, green $\left(\right.$Venus $\left.{ }^{+}\right)$, and blue $\left(\right.$Cerulean $\left.{ }^{+}\right)($Schambach et al., 2006; Gomez-Nicola et al., 2014). These retroviruses have traditionally been injected simultaneously as a mixture (Gomez-Nicola et al., 2014). However, we modified this methodology by injecting each retrovirus on the same coordinates at a different time point. This approach allows the labeling of three cell populations of different ages in the same animal. The experimental design used is shown in Figure $3 A$. Briefly, a retrovirus encoding Cerulean was injected 8 weeks before the animals were killed. Four weeks later, a mCherry-encoding retrovirus was stereotaxically injected, thus allowing the study of 4 -week-old adult-born DGCs. Finally, a Venus-encoding retrovirus was injected 2 weeks before the animals were killed, allowing the study of 2-week-old adult-born DGCs. At least 50 randomly selected adult-born DGCs from each genotype and cell age were reconstructed in a Nikon A1R confocal microscope $(25 \times$ oil-immersion objective). Confocal stacks of images were obtained ( $x$ - $y$ dimensions: $425.1 \mu \mathrm{m}$; $z$-axis interval: $2 \mu \mathrm{m}$ ), and $z$-projections were analyzed to determine total dendritic length and dendritic arbor branching (Sholl's analysis). All cells were traced using the NeuronJ plugin for Fiji software (ImageJ version 1.50e). Sholl's analysis was performed using the plugin ShollAnalysis for Fiji (Llorens-Martín et al., 2013; Pallas-Bazarra et al., 2017). To measure adult-born DGC migration into the granule cell layer (GCL), a perpendicular line connecting the hilar boundary and the center of the adult-born DGC nucleus was traced manually, and this distance was measured using Fiji. The percentage of cells with several primary apical dendrites and the length of the primary apical dendrite were calculated as described previously (Llorens-Martín et al., 2013; Pallas-Bazarra et al., 2016).

\section{Measurement of the density of PSDs of adult-born DGCs}

The density (number/length unit) and area of PSD95-GFP ${ }^{+}$clusters were analyzed separately for each branching order in the dendritic tree of PSD95:GFP-transduced adult-born DGCs, as described previously (Llorens-Martín et al., 2013; Pallas-Bazarra et al., 2016). A minimum of 30 segments for each branching order were studied per genotype. Confocal stacks of images were obtained in an LSM710 Zeiss confocal microscope $(63 \times$ oil-immersion objective; $x-y$ dimensions: $67.4 \mu \mathrm{m}$; $z$-axis interval: $0.2 \mu \mathrm{m})$. Two-channel stack $z$-projections were obtained. The 
dendritic length of each segment was measured and the number and area of PSD-GFP ${ }^{+}$clusters was analyzed using the semiautomatic particle analyzer plugin for Fiji software.

\section{Measurement of the area of MFTs of adult-born DGCs and quantification of the $\mathrm{Syn}^{+}$area of these terminals}

The area of individual GFP ${ }^{+}$MFTs was measured in the CA3 and the CA2 regions, as described previously (Llorens-Martín et al., 2015). A minimum of 20 stacks of images per experimental condition and region were obtained in an LSM710 Zeiss confocal microscope $(63 \times$ oilimmersion objective; $x-y$ dimensions: $100 \mu \mathrm{m} ; z$-interval: $0.5 \mu \mathrm{m}) . Z$ projections were obtained and the area of each MFT was measured manually using Fiji, as described previously (Toni et al., 2008; Pallas-Bazarra et al., 2016). The following criteria were used to select MFTs for quantification: (1) the diameter of the MFT was more than threefold greater than the diameter of the axon; (2) the MFT was connected to the axon on at least one end; and (3) the MFT was relatively isolated from other MFTs, thus ensuring accuracy of tracing (Toni et al., 2008; Pallas-Bazarra et al., 2016). A minimum of 400 MFTs per experimental condition were studied. To measure the Syn ${ }^{+}$area of MFTs, a fixed value threshold was applied to the green (Syn) channel of $z$-projection images. The resulting images were processed with the particle analyzer plugin in Fiji. The average area of individual Syn ${ }^{+}$particles is shown in the graphs.

\section{Analysis of the afferent innervation of adult-born DGCs}

To study afferent connectivity of newborn DGCs, we applied the TVAEnvA trans-synaptic tracing method (Wickersham et al., 2007a,b). Specifically, a retroviral vector (RV-Syn-GTRgp) expressing nuclear GFP, TVA receptor, and rabies virus glycoprotein (Rgp) driven by the neuronspecific synapsin promoter was used to selectively infect dividing cells ("starter cells"). Retroviral injections were performed on the right hemisphere. Next, an EnvA-pseudotyped rabies virus lacking Rgp and expressing MCherry (EnvA- $\Delta \mathrm{G}-\mathrm{MCh}$ ) was injected in the same hemisphere. RV-Syn-GTRgp retroviruses were used to label a population of starter adult-born DGCs (Vivar et al., 2012) that show the GFP signal in the nucleus. To label the cells that presynaptically innervate starter adult-born DGCs (traced cells), EnvA- $\Delta$ G-MCh rabies viruses were stereotaxically injected 4 weeks after retroviral injections. These viruses have been genetically engineered to be replication, infection, and transsynaptic transmission incompetent. The expression of TVA (the EnvA protein receptor) in the starter cells allows their infection by the EnvA$\Delta$ G-MCh rabies virus. Next, Rgp allowed EnvA- $\Delta$ G-MCh rabies viruses to be trans-synaptically transmitted in a retrograde manner. Therefore, both starter and traced cells were mCherry ${ }^{+}$. Moreover, starter cells showed a $\mathrm{GFP}^{+}$signal in the nucleus, whereas traced cells were exclusively mCherry ${ }^{+}$. To determine the number of starter cells $\left(\mathrm{GFP}^{+}\right.$ mCherry $^{+}$), confocal stacks of images were obtained at a $2 \mu \mathrm{m}$ $z$-interval. The number of starter cells was counted in four series (of eight) of sections throughout the rostrocaudal extent of the brain. Total cell numbers were obtained by multiplying cell counts by two (because the sampling probability was four of eight). The number of traced rabiesvirus-only-transduced cells $\left(\mathrm{mCherry}^{+}\right.$) per mouse was counted in four series of sections throughout the rostrocaudal extent of the brain. Within the DG, traced mature DGCs and inhibitory interneurons (DGIs) were identified based on their location and morphology. DGGs were identified on the basis of their elliptical cell body and their characteristic coneshaped tree of spiny apical dendrites. DGIs were identified by their morphology, as described previously (Freund and Buzsáki, 1996; Vivar et al., 2012; Sah et al., 2017). Mossy hilar (MH) cells were identified on the basis of their hilar location, their characteristic morphology, and by the presence of thorny excrescences covering the proximal ends of their long and thick dendritic branches (Blasco-Ibañez and Freund, 1997; van Praag et al., 2002; Sah et al., 2017). To evaluate the number of traced cells in other brain areas, sections were imaged under a LSM800 Zeiss confocal microscope $(2.5 \times$ objective, Tilescan tool). Sections were matched to the mouse brain atlas (Franklin, 2013) to determine the rostrocaudal distance from bregma. Next, higher-magnification images were obtained under a LSM800 Zeiss confocal microscope $(10 \times$ objective) for detailed morphological identification of the traced cells. Total cell numbers were obtained by multiplying cell counts by two. This number was then normalized on double-transduced cells (connectivity ratio) to take into account changes in the number of starter adult-born DGCs (Vivar et al., 2012; Deshpande et al., 2013; Bergami et al., 2015). Animals were killed 1 week after rabies virus injection. Only mouse brains with starter cells throughout the entire DG were included in these analyses (Sah et al., 2017). The experimental design is shown in Figure 5A.

\section{Measurement of glutamic acid decarboxylase $\left(G A D 65^{+}\right)$and Gephyrin $^{+}$area}

Images were obtained at randomly selected points within the sections comprising the series. Only the DAPI channel was visualized to select the locations at which images were acquired. Five confocal images comprising the three subregions of the molecular layer (ML) external molecular layer (EML), medial molecular layer (MML), and inner molecular layer (IML) and the GCL were obtained per animal in a LSM710 Zeiss confocal microscope ( $x-y$ dimensions: $340.08 \mu \mathrm{m} ; 25 \times$ oil-immersion objective). An invariant threshold for fluorescence intensity was established to analyze all images. The area of each subregion was outlined using the freehand drawing tool of Fiji. The GAD65 ${ }^{+}$or Gephyrin ${ }^{+}$area above the threshold was divided by the area of the subregion. The percentage of area above the threshold is shown in the graphs.

\section{Newborn DGC chemoactivation and CNO administration}

To induce the chemoactivation of adult-born DGCs, animals received a stereotaxic injection of GFP-hM3D- and RFP-encoding retroviruses (1:1 ratio). After the injection of these viruses, GFP-hM3D ${ }^{+} \mathrm{RFP}^{+}$, GFP$\mathrm{hM}^{-} \mathrm{D}^{-} \mathrm{RFP}^{+}$, and GFP-hM3D ${ }^{+} \mathrm{RFP}^{-}$populations of adult-born DGCs were identified. Given that the fluorescence intensity of the GFP$\mathrm{hM} 3 \mathrm{D}$ retrovirus is low, GFP-hM3D ${ }^{+} \mathrm{RFP}^{-}$cells were not analyzed and all measurements were performed on $\mathrm{RFP}^{+}$cells. Importantly, only

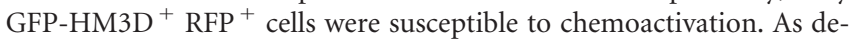
scribed previously, $\mathrm{CNO}(2 \mu \mathrm{g} / \mathrm{g})$ was diluted in water and administered in drinking water over two consecutive days in the so-called critical period of these cells (Fig. 11A) (Alvarez et al., 2016). Twenty-one days after retroviral infection, the morphology and dendritic spines of GFP$\mathrm{HM}_{3 \mathrm{D}}{ }^{+} \mathrm{RFP}^{+}$and GFP-HM3D ${ }^{-} \mathrm{RFP}^{+}$adult-born DGCs were analyzed in the red (RFP) channel. Moreover, the effect of chemoactivation on the survival of GFP-hM3D ${ }^{+}$cells was studied (Fig. 11F).

\section{Morphometric analysis of the dendritic spines of RFP ${ }^{+}$}

newborn DGCs

Dendritic spines were studied separately in GFP-HM3D ${ }^{+} \mathrm{RFP}^{+}$and GFP-HM3D ${ }^{-} \mathrm{RFP}^{+}$adult-born DGCs. Confocal stacks of images were obtained in a LSM710 Zeiss confocal microscope $(63 \times$ oil-immersion objective; $x-y$ dimensions: $67.4 \mu \mathrm{m}$; $z$-axis interval: $0.2 \mu \mathrm{m})$. The dendritic length of each segment was measured on $z$-projections, and the number of dendritic spines was counted using NeuronStudio software (CNIC, Mount Sinai School of Medicine, 2007-2009) (Rodriguez et al., 2008). Before spine analysis, images were deconvoluted using Huygens Professional software (Scientific Volume Imaging). Spines were counted from dendritic fragments located in the ML, in 10-15 $\mathrm{RFP}^{+}$cells per mouse, and in five mice per genotype and experimental condition. A minimum of 50 dendrites per experimental group were examined. Dendritic spines were detected by the software and assigned to one of the following three categories: stubby, thin, and mushroom, as described previously (Pallas-Bazarra et al., 2016, 2017). Spine density (number of spines $/ \mu \mathrm{m}$ ), the percentage of mushroom spines, the spine head and spine neck diameter, and the approximate spine length (Max-DTS) were calculated as described previously (Pallas-Bazarra et al., 2017).

\section{Measurement of phospho-Tau (AT100 and AT180) fluorescence} intensity in the dentate gyrus of human subjects

Single-plane images were acquired in a LSM710 Zeiss confocal microscope $(25 \times$ oil-immersion objective; $x-y$ dimensions: $340 \mu \mathrm{m})$. The GCL was traced on the DAPI channel using the freehand drawing tool of Fiji, and the area of this structure was calculated. Next, an invariant threshold was applied to the red channel (phospho-Tau) and the area over the threshold was calculated by the software. This area was divided by the total area measured on the DAPI channel, and the resulting values 
are represented in the graphs. Five images of randomly selected regions of the DG were obtained per subject.

\section{Statistical analysis}

Statistical analysis was performed using SPSS version 25 software. The Kolmogorov-Smirnov test was used to check the normality of sample distribution. For comparisons between two experimental groups, either a Student's $t$ test or a one-way ANOVA was used in the case of normal sample distribution, whereas a nonparametric test (Mann-Whitney $U$ test) was used in those cases in which normality could not be assumed. For comparisons between more than two experimental groups, data were analyzed by a one-way ANOVA test. In those cases in which the one-way ANOVA was statistically significant, a Fisher's LSD post hoc analysis was used to compare the differences between individual groups. Data from Sholl's analysis were studied by a repeated-measures ANOVA (Bolós et al., 2017a). Data from EE and chemoactivation experiments were analyzed by a two-way ANOVA test (genotype vs housing or genotype vs $\mathrm{CNO}$, respectively). Throughout the main text, all references to statistical significance are made to the individual factors of the two-way ANOVA test or to their interaction. A Fisher's LSD post hoc analysis was used to compare individual groups. In the figures, asterisks refer to the results of the latter analysis and indicate changes with respect to WT animals. The percentage of cells with more than one primary apical dendrite was analyzed by a $\chi^{2}$ test. Graphs represent mean values \pm SEM. A 95\% confidence interval was used for statistical comparisons.

\section{Results}

\section{Morphological alterations of DGCs in patients with FTD and} in Tau ${ }^{\mathrm{VLW}}$ mice

To examine the morphology of DGCs, we performed Golgi staining of hippocampal samples from control subjects and FTD patients. In Figure $1, A$ and $B$, representative images of the hippocampal region (left panels) and the morphology of DGCs (right panels) of control subjects (Fig. 1A) and FTD patients (Fig. $1 B)$ are shown. Sholl's analysis revealed marked alterations in the dendritic branching of DGCs in FTD patients (Greenhouse-Geisser Interaction $\left.F_{(1,7)}=73.812 ; p \leq 0.001\right)$. These cells showed increased proximal branching, whereas distal branching was dramatically reduced (Fig. 1C). Moreover, total dendritic length $\left(U_{(1,7)}=483.000 ; p \leq 0.001\right)$ (Fig. $\left.1 D\right)$ and the length of the primary apical dendrite $\left(U_{(1,7)}=1329.000 ; p \leq 0.001\right)$ (Fig. $1 E$ ) were reduced. In addition, the percentage of cells with more than one primary apical dendrite was markedly increased in these patients $\left(\chi_{(1,7)}^{2}=77.700 ; p \leq 0.001\right)$ (Fig. $\left.1 F\right)$.

To further confirm the neuropathological diagnosis of the subjects that participated in this study (shown in Fig. 2A), we analyzed Tau phosphorylation in two epitopes specifically related to FTD (Shiarli et al., 2006) (AT100 (Thr212, Ser214) (Fig. 2B-K) and AT180 (Thr231) (Fig. 2L-T) in the DG of these subjects. Representative images of phospho-Tau (AT100) staining in control subjects (Fig. 2B-F) and FTD patients (Fig. 2G-I) show that phospho-Tau (AT100) fluorescence intensity was increased in FTD patients $\left(U_{(1,7)}=0.000 ; p=0.025\right)$ (Fig. $\left.2 J\right)$. Accordingly, the number of phospho-Tau (AT-100) ${ }^{+}$DGCs was also increased $\left(U_{(1,7)}=0.000 ; p=0.025\right)$ (Fig. $\left.2 K\right)$. Representative images of phospho-Tau (AT180) staining in control subjects (Fig. $2 L-P$ ) and FTD patients (Fig. 2Q-S) show that phosphoTau (AT180) staining was increased in FTD patients $\left(U_{(1,7)}=\right.$ $0.000 ; p=0.034$ ) (Fig. $2 T$ ).

Next, we examined whether the DGCs of Tau ${ }^{\mathrm{VLW}}$ mice showed similar morphological alterations. Golgi staining revealed morphological differences between WT and Tau VLW DGCs (Fig. 1G,H). In fact, Sholl's analysis showed reduced branching in Tau ${ }^{\text {VLW }}$ DGCs (Greenhouse-Geisser Interaction $F_{(1,7)}=89.921 ; p=0.020$ ) (Fig. $\left.1 I\right)$. Although no changes in the total dendritic length were observed in Tau ${ }^{\mathrm{VLW}}$ mice $\left(U_{(1,7)}=\right.$ 3125.00; $p=0.2486$ ) (Fig. $1 J$ ), the length of the primary apical dendrite was markedly reduced $\left(U_{(1,7)}=1249.00 ; p=0.004\right)$ (Fig. $1 K)$. In contrast, no changes in the percentage of cells that exhibited several primary apical dendrites $\left(\chi_{(1,7)}^{2}=0.580 ; p=\right.$ 0.271) (Fig. 1L) were detected.

These data reveal similar morphological alterations in the DGCs of FTD patients and a mouse model of the disease.

Morphological alterations of newborn DGCs in Tau ${ }^{\mathrm{VLW}}$ mice In the light of the morphological alterations observed in the DGCs of FTD patients and Tau ${ }^{\mathrm{VLW}}$ mice, we analyzed the temporary course of these alterations by examining three populations of adult-born DGCs of distinct ages in Tau ${ }^{\mathrm{VLW}}$ mice. each of the three RGB retroviruses was stereotaxically injected in the DG of WT and Tau ${ }^{\mathrm{VLW}}$ mice at a different time point, following the experimental design shown in Figure $3 A$. In Figure $3, B-G$, representative images of 2-week-old $\left(\right.$ Venus $^{+}$) (Fig. $3 B, E$ ), 4-week-old $\left(\mathrm{mCherry}^{+}\right.$) (Fig. 3C,F), and 8-week-old (Cerulean ${ }^{+}$) (Fig. $\left.3 D, G\right)$ newborn DGCs are shown. The measurement of total dendritic length revealed differences between experimental groups $\left(F_{(5,29)}=58.349 ; p \leq 0.001\right)$ (Fig. $\left.3 H\right)$. Post hoc comparisons between WT and Tau ${ }^{\mathrm{VLW}}$ mice indicated differences in the total dendritic length of $2-(p=0.049), 4-(p \leq$ $0.001)$, and 8 - $(p=0.002)$ week-old newborn DGCs. Moreover, Sholl's analysis showed differences in dendritic branching between groups (Greenhouse-Geisser Interaction $F_{(5,29)}=15.734$; $p \leq 0.001$ ) (Fig. 3I-K). Multiple-comparisons post hoc analysis between genotypes revealed no differences in 2-week-old newborn DGCs $(p=0.151)$ (Fig. 3I), whereas marked differences were observed in 4-week-old $(p \leq 0.001)$ (Fig. $3 J)$ and 8-weekold $(p=0.045)$ (Fig. $3 K)$ newborn DGCs. Accordingly, the length of the primary apical dendrite varied between experimental groups $\left(F_{(5,29)}=8.932 ; p \leq 0.001\right)$ (Fig. $\left.3 L\right)$. Post hoc analysis revealed a decrease in this parameter in 4 -week-old $(p \leq 0.001)$ and 8 -week-old $(p=0.004)$ newborn DGCs of Tau ${ }^{\text {VLW }}$ mice, whereas no differences in this parameter were detected in 2 -week-old DGCs $(p=0.976)$. Moreover, the percentage of cells with more than one primary apical dendrite varied between experimental conditions $\left(\chi_{(5,29)}^{2}=29.860 ; p \leq 0.001\right)$. This percentage was greater in 2 -week-old $(p=0.048), 4$-week-old $(p=$ 0.007 ), and 8-week-old ( $p \leq 0.001$ ) newborn DGCs (Fig. 3M). The migration of newborn DGCs showed differences between experimental conditions $\left(F_{(5,29)}=3.420 ; p=0.005\right)$. Post hoc analysis revealed a transient increase in migration in 2-week-old newborn DGCs of Tau ${ }^{\mathrm{VLW}}$ mice $(p=0.039)$, whereas no differences were found in 4 -week-old $(p=0.997)$ and 8 -week-old $(p=0.982)$ newborn DGCs (Fig. $3 N)$.

These data show that the morphological maturation of adultborn DGCs is altered in Tau ${ }^{\mathrm{VLW}}$ mice.

\section{Afferent and efferent connectivity of newborn DGCs is altered in Tau ${ }^{\mathrm{VLW}}$ mice}

To analyze the excitatory afferent connectivity of adult-born DGCs in WT and Tau ${ }^{\mathrm{VLW}}$ mice, a retrovirus that encodes PSD95: GFP was stereotaxically injected into the DG of these animals. Eight weeks later, they were killed and the PSDs of the adult-born DGCs were examined separately in each branching order of the dendritic tree (Fig. 4A). The number of PSDs was dramatically reduced in Tau ${ }^{\mathrm{VLW}}$ animals throughout the whole dendritic tree (Fig. 4B-D). A marked reduction was observed in the density of PSDs in second $\left(F_{(1,9)}=13.408 ; p \leq 0.001\right)$, third $\left(F_{(1,9)}=\right.$ $16.639 ; p \leq 0.001)$, fourth $\left(F_{(1,9)}=21.252 ; p \leq 0.001\right)$ and fifth 
$\left(F_{(1,9)}=9.306 ; p=0.004\right)$ branching-order dendrites (Fig. $\left.4 D\right)$. Moreover, alterations in PSD area were observed in fifth $\left(F_{(1,9)}=\right.$ 40.024; $p \leq 0.001)$ branching-order dendrites, whereas no changes in this parameter were observed in second $\left(F_{(1,9)}=\right.$ $0.273 ; p=0.601)$, third $\left(F_{(1,9)}=4.003 ; p=0.055\right)$, or fourth $\left(F_{(1,9)}=1.206 ; p=0.272\right)$ orders (Fig. $\left.4 E\right)$. These data indicate that the afferent connectivity of adult-born DGCs is altered in Tau ${ }^{\mathrm{VLW}}$ mice.

To study the efferent connectivity of adult-born DGCs in WT and Tau ${ }^{\mathrm{VLW}}$ mice, a retrovirus that encodes Syn:GFP was stereotaxically injected into the DG of these animals. The mice were killed 8 weeks later, and the MFTs of adult-born DGCs were examined separately in the CA3 and the CA2 regions (Fig. 4A). A marked reduction of individual MFT area was observed in Tau ${ }^{\text {VLW }}$ mice (Fig. $4 F-K$ ). These differences were observed in the CA3 $\left(F_{(1,9)}=191.418 ; p \leq 0.001\right)$ (Fig. $\left.4 J\right)$ and the CA2 $\left(F_{(1,9)}=\right.$ $12.115 ; p \leq 0.001$ ) (Fig. $4 K$ ) hippocampal subfields. The area of $\mathrm{Syn}^{+}$particles was reduced in Tau ${ }^{\mathrm{VLW}}$ animals, both in the CA3 $\left(F_{(1,9)}=17.714 ; p \leq 0.001\right)$ (Fig. $\left.4 L\right)$ and the CA2 $\left(F_{(1,9)}=8.722\right.$; $p=0.003$ ) (Fig. $4 M$ ) regions. These data indicate that the efferent connectivity of adult-born DGCs is also altered in Tau VLW animals.

Together, the alterations in the afferent and efferent connectivity of adult-born Tau ${ }^{\mathrm{VLW}}$ DGCs suggest that the functional maturation of these cells is impaired in this animal model of FTD.

\section{Afferent innervation of newborn DGCs is altered in Tau ${ }^{\mathrm{VLW}}$ mice}

In the light of the alterations in the excitatory afferent connectivity of adult-born DGCs in Tau ${ }^{\mathrm{VLW}}$ mice suggested by the decreased number and size of PSDs, we investigated whether the afferent projections to these cells were also altered. We used a genetically modified rabies virus, which allowed the retrograde monosynaptic tracing of these cells (Vivar et al., 2012). Figure 5A shows the experimental design. Briefly, a retrovirus that encodes GFP with a nuclear signal was stereotaxically injected in the DG of WT and Tau ${ }^{\mathrm{VLW}}$ mice to label a population of starter adult-born DGCs. Four weeks later, a rabies virus that encodes mCherry was stereotaxically injected at the same coordinates. Animals were killed 1 week later. As expected, the number of $\mathrm{GFP}^{+}$starter cells was reduced in Tau ${ }^{\mathrm{VLW}}$ animals $\left(U_{(1,9)}=6.000 ; p=0.043\right)$ (Fig. $5 B)$, which showed a reduction in the survival of adult-born DGCs (Llorens-Martín et al., 2011). In contrast, no changes in the number of traced cells $\left(U_{(1,9)}=1.000 ; p=0.127\right)$ (Fig. $5 C$ ) or in the ratio traced/starter cells $\left(t_{(1,9)}=1.003 ; p=0.373\right)($ Fig. $5 D)$ were found. Representative images of traced cells in the Entorhinal cortex cells of WT (Fig. $5 E$ ) and Tau ${ }^{\text {VLW }}$ mice (Fig. $5 F$ ) are shown. Quantification of the number of cells located in different brain regions revealed a decrease in the connectivity ratio of both distal brain regions (distal) $\left(t_{(1,9)}=23.979 ; p \leq 0.001\right)$ and the hippocampus (HC) $\left(U_{(1,9)}=6.000 ; p=0.050\right)$ in Tau ${ }^{\mathrm{VLW}}$ mice, whereas no differences were found in the connectivity ratio of the DG $\left(U_{(1,9)}=1.000 ; p=0.200\right)$ (Fig. $\left.5 G\right)$. Moreover, a specific analysis of the local innervation of Tau ${ }^{\mathrm{VLW}}$ adult-born DGCs unveiled that these cells showed reduced innervation from excitatory DGCs $\left(U_{(1,9)}=0.000 ; p=0.050\right)$ and glutamatergic $\mathrm{MH}$ cells $\left(U_{(1,9)}=0.000 ; p=0.046\right)$ (Fig. $\left.5 H\right)$. In contrast, the connectivity ratio of DGIs was increased in Tau ${ }^{\mathrm{VLW}}$ adult-born DGCs $\left(t_{(1,9)}=2.292 ; p=0.043\right)$. In fact, $60 \%$ of traced cells in these animals were DGIs. In Figure $5, I-J$, representative images of starter (blue $\left(\mathrm{GFP}^{+} \mathrm{mCherry}^{-}\right.$) and green $\left(\mathrm{GFP}^{+}\right.$mCherry $^{+}$) triangles) and traced (white triangles) cells of WT (Fig. 5I) and
Tau ${ }^{\mathrm{VLW}}$ mice (Fig. $5 J$ ) illustrate the relative abundance of afferent connections with granule cells in WT mice (Fig. 5I). In contrast, most of the afferent connections received by Tau VLW newborn DGCs corresponded to DGIs (Fig. 5J). Moreover, Figure $5, K-L$, show representative images of the morphology of traced DGIs in WT (Fig. $5 K$ ) and Tau ${ }^{\mathrm{VLW}}$ (Fig. $5 L$ ) mice. As previously mentioned, the adult-born DGCs of Tau ${ }^{\mathrm{VLW}}$ mice received reduced innervation from distal brain regions (Fig. 5M$N)$.

These data suggest that the afferent innervation of adult-born DGCs is impaired in this animal model of FTD. These impairments include a marked disconnection from distal brain regions, a decrease in excitatory local innervation, and a considerable increase in the local sources of inhibitory innervation.

\section{Tau ${ }^{\mathrm{VLW}}$ mice and patients with FTD show an increase in the} expression of inhibitory synapse markers in the dentate gyrus To further characterize this increase in inhibitory innervation, we quantified the expression of both presynaptic (GAD65) (Fig. $6 A-C$ ) and postsynaptic (Gephyrin) (Fig. 6D-F) markers of inhibitory synapses in various subregions of the DG in WT and $\mathrm{Tau}^{\mathrm{VLW}}$ mice. The expression of GAD65 was either increased or showed a trend toward an increase in the GCL $\left(t_{(1,9)}=-3.858\right.$; $p=0.005)$, and in the inner layer $(\mathrm{IML})\left(t_{(1,9)}=-2.054 ; p=\right.$ $0.077)$, medial layer $(\mathrm{MML})\left(t_{(1,9)}=-2.704 ; p=0.035\right)$, and outer layer $(\mathrm{EML})\left(t_{(1,9)}=-1.662 ; p=0.063\right)$ of the molecular layer (ML) (Fig. 6A-C). In agreement, the expression of the postsynaptic marker of inhibitory synapses Gephyrin increased in the $\operatorname{EML}\left(t_{(1,9)}=-2.401 ; p=0.016\right)$, although no changes in this parameter were found in the GCL $\left(t_{(1,9)}=0.389 ; p=0.706\right)$, IML $\left(t_{(1,9)}=-0.267 ; p=0.798\right)$ or $\operatorname{MML}\left(t_{(1,9)}=-0.737 ; p=0.483\right)$ (Fig. 6D-F).

We next addressed whether this increase was also present in FTD patients. we analyzed the expression of GAD65 (Fig. 6G-I) and Gephyrin (Fig. 6J-L) in the DG of control subjects and FTD patients. In Figure 6, $H-I$, representative images of GAD65 staining show either an increase or a trend toward an increase in the GCL $\left(U_{(1,7)}=0.000 ; p=0.05\right)$, the MML $\left(U_{(1,7)}=0.000 ; p=\right.$ $0.063)$, and the EML $\left(U_{(1,7)}=0.000 ; p=0.063\right)$ of FTD patients, whereas no changes in GAD65 staining were found in the IML $\left(U_{(1,7)}=4.000 ; p=0.480\right)$ (Fig. $\left.6 G\right)$. In agreement, the expression of the postsynaptic marker of inhibitory synapses Gephyrin was either increased or showed a trend toward an increase the $\operatorname{IML}\left(U_{(1,7)}=1.000 ; p=0.053\right)$, the $\operatorname{MML}\left(U_{(1,7)}=0.000 ; p=\right.$ $0.025)$, and the EML $\left(U_{(1,7)}=0.000 ; p=0.025\right)$, although no changes in this parameter were found in the GCL $\left(U_{(1,7)}=4.000\right.$; $p=0.480$ ) of these patients (Fig. $6 J-L$ ).

Together, these data further support the notion that an increase in inhibitory innervation of the DG occurs both in Tau VLW mice and FTD patients.

\section{$\mathrm{Tau}^{\mathrm{VLW}}$ mice show a higher number of $\mathrm{NPY}^{+}$interneurons in the granule cell layer}

Given the increased DG inhibitory innervation observed in Tau ${ }^{\mathrm{VLW}}$ mice, we examined the number of distinct subpopulations of interneurons in the GCL of these animals (Fig. 7). The number of $\mathrm{PV}^{+}$interneurons did not differ between genotypes (Fig. $7 A-C)\left(t_{(1,9)}=-1.097 ; p=0.287\right)$. In contrast, the number of $\mathrm{NPY}^{+}$interneurons in the GCL of Tau ${ }^{\mathrm{VLW}}$ mice showed a selective increase (Fig. $7 D-F)\left(U_{(1,9)}=17.000 ; p=0.043\right)$. 
Tau ${ }^{\mathrm{VLW}}$ mice show alterations in the expression of neuronal activation markers in the dentate gyrus

Given the increased inhibitory innervation and number of NPY ${ }^{+}$ interneurons in the DG of Tau ${ }^{\mathrm{VLW}}$ mice, we examined whether DGC activation is altered in these mice. we counted the number of cells that showed nuclear staining with three distinct markers of neuronal activation, the early immediate genes cfos, Arc, and egr-1 (Fig. 8). Although no changes in the number of $\mathrm{cfos}^{+}$(Fig. $8 A-C)\left(t_{(1,9)}=-0.821 ; p=0.424\right)$ or $\mathrm{Arc}^{+}($Fig. $8 D-F)\left(t_{(1,9)}=\right.$ $-0.114 ; p=0.910)$ DGCs were observed, the GCL of Tau ${ }^{\text {LW }}$ mice showed a reduced number of egr-1-expressing DGCs (Fig. $8 G-I)\left(U_{(1,9)}=2.000 ; p=0.032\right)$.

\section{Rate of adult hippocampal neurogenesis is responsive to the stimulatory effects of environmental enrichment in Tau VLW mice}

Hippocampal plasticity is positively modulated by EE (Kempermann et al., 1997; Brown et al., 2003). Thus, we examined whether this stimulus reverses the impairments observed in the adult-born DGCs of Tau ${ }^{\text {VLW }}$ mice. WT and Tau ${ }^{\mathrm{VLW}}$ mice were exposed to an 8-week period of EE or to control housing $(\mathrm{CH})$ conditions (Fig. 9A). To study the diverse processes encompassed by AHN, the number of $\mathrm{IdU}^{+}$, apoptic fractin ${ }^{+}$cells and DCX ${ }^{+}$ immature neurons was counted. Representative images of 8-week-old $\mathrm{IdU}^{+}$(Fig. 9B-E) cells illustrate differences in the number of cells found between experimental groups $\left(F_{(3,27)}=\right.$ 7.198; $p \leq 0.001$ ) (Fig. 9J). As described previously (LlorensMartín et al., 2011), Tau ${ }^{\text {VLW }}$ animals showed a reduced number of these cells $\left(F_{(1,27)}=9.655 ; p=0.005\right)$, a finding that further supports the decreased number of starter cells observed in the rabies viruses experiments. However, EE increased the number of these cells in both genotypes $\left(F_{(1,27)}=13.057 ; p \leq 0.001\right)$ (Fig. $9 J)$. Accordingly, the number of fractin ${ }^{+}$cells differed between experimental groups $\left(F_{(3,32)}=24.841 ; p \leq 0.001\right)$, being higher in Tau ${ }^{\mathrm{VLW}}$ animals $\left(F_{(1,27)}=36.875 ; p \leq 0.001\right)$ (Llorens-Martín et al., 2011). This increase was counteracted by EE (Interaction $F_{(1,32)}=10.244 ; p=0.003$ ) (Fig. $\left.9 K\right)$. Moreover, the number of DCX $^{+}$neuroblasts differed between experimental groups $\left(F_{(3,26)}\right.$ $=56.597 ; p \leq 0.001$ ) (Fig. $9 F-I, L)$. Tau ${ }^{\mathrm{VLW}}$ mice showed a reduction in the number of these cells $\left(F_{(1,26)}=100.184 ; p \leq 0.001\right)$ (Llorens-Martín et al., 2011). EE increased the number of DCX ${ }^{+}$ cells in in WT and Tau ${ }^{\mathrm{VLW}}$ mice $\left(F_{(1,26)}=48.589 ; p \leq 0.001\right)$, although this increase was greater in the former (Interaction $\left.F_{(1,26)}=27.573 ; p \leq 0.001\right)$.

Together, these data indicate that several components of AHN in Tau ${ }^{\mathrm{VLW}}$ mice are sensitive to the stimulatory actions of EE.

\section{Environmental enrichment completely reverses the morphological alterations of newborn DGCs and partially restores their connectivity in Tau ${ }^{\mathrm{VLW}}$ mice}

Having confirmed that the rate of AHN of Tau ${ }^{\mathrm{VLW}}$ mice was responsive to the stimulatory actions of EE, we studied the capacity of EE to counteract the alterations in the morphological and functional maturation of adult-born DGCs in these animals (Fig. 10). a PSD95:GFP-encoding retrovirus was stereotaxically injected into the DG of WT and Tau ${ }^{\mathrm{VLW}}$ mice. Mice were exposed to an 8-week period of $\mathrm{EE}$ or $\mathrm{CH}$ conditions (Fig. 10A). The morphology and PSDs of adult-born DGCs of the different experimental conditions are shown (Fig. 10B-E). Total dendritic length differed between experimental groups $\left(F_{(3,19)}=5.170 ; p=\right.$ 0.002 ) (Fig. 10F). Tau ${ }^{\mathrm{VLW}}$ mice exhibited a reduction in this parameter $\left(F_{(1,19)}=8.536 ; p=0.004\right)$. However, EE reversed this alteration (Interaction $F_{(1,19)}=4.309 ; p=0.039$ ). Accordingly, the length of the primary apical dendrite differed between experimental conditions $\left(F_{(3,19)}=22.068 ; p \leq 0.001\right)$. Tau ${ }^{\mathrm{VLW}}$ mice showed a reduced length $\left(F_{(1,19)}=38.465 ; p \leq 0.001\right)$, and this decrease was counteracted by EE (Interaction $F_{(1,19)}=24.024$; $p \leq 0.001$ ) (Fig. 10G). Moreover, the percentage of cells with more than one primary apical dendrite showed differences between experimental groups $\left(\chi_{3,19}^{2}=11.014 ; p=0.026\right)$. This percentage was greater in CH Tau ${ }^{\mathrm{VLW}}$ mice $(p=0.048)$, and this increase was reversed by EE (CH Tau ${ }^{\mathrm{VLW}}$ vs EE Tau ${ }^{\mathrm{VLW}}$ mice, $p \leq 0.001$ ) (Fig. 10H). Finally, Sholl's analysis revealed differences between experimental groups (Greenhouse-Geisser Interaction $\left.F_{(3,19)}=3.631 ; p \leq 0.001\right)$. Multiple-comparisons post hoc analysis indicated alterations in the dendritic branching of Tau ${ }^{\mathrm{VLW}}$ mice $(p \leq 0.001)$ and that EE reversed these alterations $\left(\mathrm{CH} \mathrm{Tau}^{\mathrm{VLW}}\right.$ vs EE Tau ${ }^{\mathrm{VLW}}$ mice, $\left.p=0.010\right)$ (Fig. 10I).

The density of PSDs in second $\left(F_{(3,19)}=4.819 ; p=0.004\right)$, third $\left(F_{(3,19)}=15.654 ; p \leq 0.001\right)$, fourth $\left(F_{(3,19)}=22.505 ; p \leq\right.$ $0.001)$ and fifth $\left(F_{(3,19)}=10.371 ; p \leq 0.001\right)$ branching-order dendrites differed between experimental groups (Fig. 10J). EE increased the number of these structures in WT dendrites of fourth $\left(F_{(1,9)}=22.903 ; p \leq 0.001\right)$ and fifth $\left(F_{(1,19)}=5.187 ; p=\right.$ $0.025)$ branching orders. Tau ${ }^{\mathrm{VLW}}$ mice showed a reduction in the number of PSDs in the dendrites of second $\left(F_{(1,9)}=10.451 ; p=\right.$ $0.002)$, third $\left(F_{(1,19)}=40.477 ; p \leq 0.001\right)$, fourth $\left(F_{(1,19)}=\right.$ $39.845 ; p \leq 0.001)$ and fifth $\left(F_{(3,19)}=24.834 ; p \leq 0.001\right)$ branching orders. These alterations were reversed by EE in dendrites of second $\left(\mathrm{CH}\right.$ Tau ${ }^{\mathrm{VLW}}$ vs EE Tau ${ }^{\mathrm{VLW}}$ mice, $\left.p=0.045\right)$, and fourth $\left(\mathrm{CH}\right.$ Tau ${ }^{\text {VLW }}$ vs EE Tau ${ }^{\text {VLW }}$ mice, $\left.p=0.020\right)$ branching orders.

The area of CA3 MFTs differed between experimental groups $\left(F_{(3,19)}=112.453 ; p \leq 0.001\right)$ (Fig. $\left.10 K-N, S\right)$. Tau ${ }^{\mathrm{VLW}}$ mice showed a reduced MFT area in the CA3 region $\left(F_{(1,19)}=112.453\right.$; $p \leq 0.001$ ), and this reduction was counteracted by EE (Interaction $\left.F_{(1,19)}=218.240 ; p \leq 0.001\right)$. Moreover, differences between experimental groups were found in MFT area in the CA2 field $\left(F_{(3,19)}=317.055 ; p \leq 0.001\right.$ ) (Fig. $\left.10 O-R, T\right)$. Tau ${ }^{\mathrm{VLW}}$ mice showed a reduced MFT area in this region $\left(F_{(1,19)}=293.082 ; p \leq\right.$ $0.001)$. EE increased the area of CA2 MFT in WT mice but did not have any effect on Tau ${ }^{\mathrm{VLW}}$ mice (interaction $F_{(1,19)}=181.407$; $p \leq 0.001)$.

These data show that EE completely reverses the morphological alterations caused by Tau ${ }^{\text {VLW }}$. Moreover, EE partially restored the afferent and efferent connectivity of these cells.

\section{Chemoactivation completely reverses the morphological alterations of newborn DGCs and partially restores their connectivity in Tau ${ }^{\mathrm{VLW}}$ mice}

Given that the effects of EE on the maturation of adult-born DGCs are mimicked by the chemoactivation of these cells during their so-called critical period (Temprana et al., 2015), we tested the capacity of chemoactivation to reverse the morphological and functional alterations of this cell population in Tau ${ }^{\mathrm{VLW}}$ mice. retroviruses encoding hM3D:GFP and RFP were stereotaxically injected into the DG of these animals (Fig. $11 B-E$ ). CNO was administered during the critical period of these cells (Fig. 11A), We first analyzed whether chemoactivation altered the survival of hM3D:GFP ${ }^{+}$transduced cells. we counted the density of hM3D: $\mathrm{GFP}^{+}$cells in the GCL of WT and Tau ${ }^{\mathrm{VLW}}$ mice, in the absence and presence of $\mathrm{CNO}$ (Fig. $11 F$ ). Marked differences were observed between experimental groups $\left(F_{(3,19)}=5.080 ; p=0.012\right)$. As shown, CNO had no effect on the survival of newborn DGCs $\left(F_{(1,19)}=0.022 ; p=0.884\right)$. In contrast, Tau ${ }^{\mathrm{VLW}}$ DGCs exhibited reduced survival $\left(F_{(1,19)}=15.053 ; p \leq 0.001\right)$, which is consistent with the results obtained with thymidine analogs (Fig. 9J). 
Next, we examined several morphometric features of control and chemoactivated newborn DGCs of both genotypes. The total dendritic length differed between experimental groups (double transduced cells (hM3D:GFP ${ }^{+} / \mathrm{RFP}^{+}$): $F_{(3,19)}=53.746 ; p \leq$ 0.001; Single transduced cells $\left(\mathrm{hM} 3 \mathrm{D}: \mathrm{GFP}^{-} / \mathrm{RFP}^{+}\right): F_{(3,19)}=$ 57.781; $p \leq 0.001)$. Chemoactivation increased this parameter in double transduced cells $\left(F_{(1,19)}=95.943 ; p \leq 0.001\right)$ and reversed the alterations observed in Tau ${ }^{\mathrm{VLW}}$ mice ( Tau ${ }^{\mathrm{VLW}}+\mathrm{CNO}$ vs $\mathrm{Tau}^{\mathrm{VLW}}+$ vehicle, $\left.p \leq 0.001\right)$. In contrast, this reversal did not occur in single transduced cells ( Tau ${ }^{\mathrm{VLW}}+\mathrm{CNO}$ vs Tau ${ }^{\mathrm{VLW}}+$ vehicle, $p=1.000$ ) (Fig. 11G). Accordingly, Sholl's analysis revealed differences between experimental groups (double transduced cells: Greenhouse-Geisser Interaction $F_{(3,19)}=18.886$; $p \leq 0.001$; single transduced cells: Greenhouse-Geisser Interaction $F_{(3,19)}=14.215 ; p \leq 0.001$ ) (Fig. 11H). Multiplecomparisons post hoc analysis between genotypes in double transduced cells showed that CNO treatment increased the dendritic branching of WT neurons (WT + CNO vs WT + vehicle, $p \leq 0.001)$; that Tau ${ }^{\mathrm{VLW}}$ mice showed a reduced branching $(p \leq$ $0.001)$; and that chemoactivation reversed these alterations $\left(\mathrm{Tau}^{\mathrm{VLW}}+\mathrm{CNO}\right.$ vs Tau ${ }^{\mathrm{VLW}}+$ vehicle, $\left.p \leq 0.001\right)$. In contrast, $\mathrm{CNO}$ treatment had no effect on single transduced cells of WT $(\mathrm{WT}+\mathrm{CNO}$ vs WT + vehicle, $p=0.324)$ or Tau $^{\mathrm{VLW}}\left(\mathrm{Tau}^{\mathrm{VLW}}+\right.$ $\mathrm{CNO}$ vs Tau ${ }^{\mathrm{VLW}}+$ vehicle, $p=1.000$ ) mice (Fig. 11I). The analysis of adult-born DGC migration revealed differences between experimental groups (double transduced cells: $F_{(3,19)}=$ 38.505; $p \leq 0.001$; single transduced cells: $F_{(3,19)}=13.615 ; p \leq$ 0.001 ) (Fig. 11J). Tau ${ }^{\text {VLW }}$ mice showed an increase in this parameter (double transduced cells: $F_{(1,19)}=36.474 ; p=0.004$; single transduced cells: $\left.F_{(1,19)}=38.285 ; p \leq 0.001\right)$. In double transduced cells, chemoactivation increased adult-born DGC migration in WT animals and normalized this parameter in Tau VLW mice (Interaction $F_{(1,19)}=51.957 ; p \leq 0.001$ ). CNO administration had no effect on single transduced cells $\left(F_{(1,19)}=0.553 ; p=\right.$ 0.458 ) (Fig. 11J). The length of the primary apical dendrite varied between experimental groups (double transduced cells: $F_{(3,19)}=$ 48.512; $p \leq 0.001$; single transduced cells: $F_{(3,19)}=18.728 ; p \leq$ $0.001)$ (Fig. $11 \mathrm{~K})$. Chemoactivation increased this parameter in double transduced cells of animals of both genotypes $\left(F_{(1,19)}=\right.$ $114.887 ; p \leq 0.001)$. In contrast, $\mathrm{CNO}$ administration had no effect on single transduced cells $\left(F_{(1,19)}=0.024 ; p=0.878\right)$. The percentage of cells with several primary apical dendrites varied between experimental groups (double transduced cells: $\chi_{3,19}^{2}=$ 35.018; $p \leq 0.001$; single transduced cells: $\chi_{3,19}^{2}=27.068 ; p \leq$ 0.001 ) (Fig. 11L). Tau ${ }^{\text {VLW }}$ mice showed an increase in this parameter (double and single transduced cells: $p \leq 0.001$ ), which was counteracted by chemoactivation in double transduced cells $\left(\mathrm{Tau}^{\mathrm{VLW}}+\mathrm{CNO}\right.$ vs Tau ${ }^{\mathrm{VLW}}+$ vehicle, $\left.p \leq 0.001\right)$. In contrast, CNO administration had no effect on single transduced cells $\left(\mathrm{Tau}^{\mathrm{VLW}}+\right.$ CNO vs Tau ${ }^{\mathrm{VLW}}+$ vehicle, $\left.p=0.536\right)$.

High-power magnification images show the dendritic spines of double transduced adult-born DGCs from the different experimental conditions (Fig. 11M-P). In double transduced cells, the density of dendritic spines varied between experimental groups $\left(F_{(3,19)}=13.456 ; p \leq 0.001\right)$. Tau ${ }^{\mathrm{VLW}}$ adult-born DGCs showed a reduction in the density of these structures $\left(F_{(1,19)}=5.748 ; p=\right.$ $0.018)$. Chemoactivation increased this parameter in WT animals, but had no effect on Tau ${ }^{\mathrm{VLW}}$ mice (Interaction $F_{(1,19)}=$ 11.354; $p \leq 0.001$ ) (Fig. 11Q). Analysis of the percentage of mushroom spines revealed differences in double transduced cells between experimental groups $\left(F_{(3,19)}=6.028 ; p \leq 0.001\right)$. $\mathrm{Tau}^{\mathrm{VLW}}$ mice showed a decrease in the percentage of this type of spine $\left(F_{(1,9)}=12.348 ; p \leq 0.001\right)$. Chemoactivation increased the percentage of these structures in both genotypes $\left(F_{(1,19)}=5.172\right.$; $p=0.024$; Interaction $F_{(1,19)}=0.297 ; p=0.586$ ) (Fig. $11 R$ ). Morphometric analysis of the dendritic spines of double transduced cells revealed differences in the diameter of the spine head $\left(F_{(3,19)}=5.141 ; p=0.002\right)$ (Fig. $\left.11 S\right)$ and spine neck $\left(F_{(3,19)}=\right.$ 10.995; $p \leq 0.001$ ) (Fig. 11T), and in the length of these structures $($ Max-DTS $)\left(F_{(3,19)}=76.883 ; p \leq 0.001\right)($ Fig. $11 U)$ between experimental conditions. Tau ${ }^{V L W}$ mice showed a reduction in spine head $\left(F_{(1,19)}=5.919 ; p=0.015\right)$ (Fig. 11S) and spine $\operatorname{neck}\left(F_{(1,19)}=30.287 ; p \leq 0.001\right)$ (Fig. $\left.11 T\right)$ diameter, and in the length of these structures (Max-DTS) $\left(F_{(1,19)}=68.255 ; p \leq\right.$ 0.001 ) (Fig. $11 U$ ). Chemoactivation did not modify the diameter of the head $\left(F_{(1,19)}=2.698 ; p=0.101\right)$ (Fig. $\left.11 S\right)$ or neck $\left(F_{(1,19)}\right.$ $=3.101 ; p=0.078$ ) (Fig. $11 T$ ) of dendritic spines; however, it caused a reduction in the length of these structures (Max-DTS) $\left(F_{(1,19)}=65.955 ; p \leq 0.001\right)$ (Fig. $\left.11 U\right)$. The alterations in the morphometric properties of dendritic spines observed in Tau ${ }^{\mathrm{VLW}}$ adult-born DGCs were not reversed by chemoactivation (diameter of spine head $\left(\mathrm{Tau}^{\mathrm{VLW}}+\mathrm{CNO}\right.$ vs Tau ${ }^{\mathrm{VLW}}+$ vehicle, $p=$ 0.864) (Fig. 11S) and spine neck (Tau ${ }^{\mathrm{VLW}}+\mathrm{CNO}$ vs Tau ${ }^{\mathrm{VLW}}+$ vehicle, $p=0.056$ ) (Fig. 11T), and length of these structures (Max-DTS) $\left(\mathrm{Tau}^{\mathrm{VLW}}+\mathrm{CNO}\right.$ vs Tau ${ }^{\mathrm{VLW}}+$ vehicle, $\left.p=0.401\right)$ (Fig. 11U)).

These data reveal that chemoactivation completely reverses the morphological alterations observed in the adult-born DGCs of Tau ${ }^{\mathrm{VLW}}$ mice and partially restores the afferent connectivity of these cells.

\section{Discussion}

The hippocampus is particularly affected in most forms of FTD (Senut et al., 1991; Bird et al., 1999; Laakso et al., 2000; Nishimura et al., 2000; Chang et al., 2004; Engel et al., 2008; Bandopadhyay et al., 2014). This region of the brain hosts one of the most unique phenomena in the adult mammalian brain, the addition of new neurons throughout lifetime (Altman and Das, 1965; Eriksson et al., 1998; Moreno-Jiménez et al., 2019). This process, known as $\mathrm{AHN}$, is a form of neural plasticity involved in hippocampaldependent learning and mood regulation (Sahay and Hen, 2007; Sahay et al., 2011). In fact, numerous animal models of neurodegenerative diseases characterized by memory impairments also exhibit a reduction in AHN and alterations in emotional behavior (Kuhn et al., 2007; Lazarov and Marr, 2010, 2013; LlorensMartín et al., 2013).

Here we report, for the first time, striking morphological alterations in the DGCs of FTD patients. To test the involvement of pathological forms of Tau in this aberrant morphological phenotype of this cell population, we used a mouse model of FTD, Tau ${ }^{\text {VLW }}$ mice. Using RGB retroviruses (Schambach et al., 2006; Gomez-Nicola et al., 2014), we observed a morphological phenotype in adult-born DGCs of Tau ${ }^{\mathrm{VLW}}$ mice identical to that in DGCs of FTD patients. Moreover, Golgi staining confirmed this morphological phenotype in the general population of DGCs. These morphological alterations were paralleled by a remarkable impairment of adult-born DGC connectivity in Tau ${ }^{\mathrm{VLW}}$ mice. In this regard, these cells showed a reduced number and size of PSDs, and a decrease in the area of MFTs and Syn ${ }^{+}$clusters. These data are in agreement with previous studies that point to the crucial roles played by Tau at the synapse (Ittner et al., 2010; Ittner and Götz, 2011).

In the light of the alterations in the afferent connectivity of adult-born DGCs observed in Tau ${ }^{\mathrm{VLW}}$ mice, we addressed whether the presynaptic innervation of these cells was altered. Monosynaptic retrograde tracing (Vivar et al., 2012) revealed 
alterations in both distal and local sources of adult-born DGC innervation in Tau ${ }^{\mathrm{VLW}}$ animals. In the latter case, afferent connections established with inhibitory interneurons were predominant. Consistent with this increased afferent innervation by interneurons, we observed an increase in both presynaptic and postsynaptic markers of inhibitory synapses in the ML of Tau VLW mice and FTD patients. This increase was paralleled by an augmentation in the number of NPY ${ }^{+}$interneurons in the former. In contrast, the population of $\mathrm{PV}^{+}$interneurons remained unaltered, as has been shown to occur in patients with FTD (Ferrer, 1999). In agreement with the increased inhibitory innervation, a general decrease in the activation of the GCL was evidenced by a reduction in the number of cells that were positive for the neuronal activation marker egr-1 in Tau ${ }^{\mathrm{VLW}}$ mice, although no changes in the expression of cfos or Arc were observed in this region. In this regard, mounting evidence suggests that the alterations in GABAergic neurotransmission are an early and prominent factor that drives the progression of neuropathological alterations in neurodegenerative diseases (Mitew et al., 2013; Wu et al., 2014; Govindpani et al., 2017). Given the marked cell loss of other neuronal populations, it has been suggested that an imbalanced inhibition/excitation ratio is an early symptom of several neurodegenerative conditions (Mitew et al., 2013; Govindpani et al., 2017). In fact, the brain parenchyma of patients with dementia shows increased extracellular concentrations of GABA (Mountjoy et al., 1984; Ellison et al., 1986; Li et al., 2016). Moreover, increased GAD65 expression has been reported in patients with Alzheimer's disease and in animal models of this condition (Bell et al., 2003). Interestingly, cortical GABAergic interneurons are in a hypermetabolic state in a mouse model of FTD (Nilsen et al., 2013). In addition, patients with this disease show a marked synaptic reorganization of inhibitory connections and subsequent alteration of DGC excitability (Bandopadhyay et al., 2014). These data are in agreement with our own results, which show an increase in the inhibitory innervation of the DG both in Tau VLW mice and in FTD patients, and a reduced activation of DGCs in the former.

AHN acts as a sensor of external stimuli (Llorens-Martín et al., 2009 , 2010). Enriched environments boost the survival and maturation of adult-born DGCs in rodents (Kempermann et al., 1997; van Praag et al., 2000; Brown et al., 2003), both in WT animals and in models of neurodegenerative diseases (van Praag, 2008, 2009; Choi et al., 2016). Our own data show that EE enhances the rate of AHN in Tau ${ }^{\text {VLW }}$ mice. Moreover, the morphological alterations observed in the adult-born DGCs of these animals were completely reversed by EE. Although the precise molecular and cellular mechanisms triggered by EE are still poorly understood, seminal work by Alvarez et al. demonstrated that the stimulatory effects of EE on adult-born DGC maturation are mediated by a disynaptic feedback network involving mature DGCs, $\mathrm{PV}^{+}$interneurons, and adult-born DGCs (Alvarez et al., 2016). Alvarez et al. proposed that EE increases the activation of mature DGCs, which in turn activate GABAergic $\mathrm{PV}^{+}$interneurons. GABA release by the latter exerts a stimulatory, trophic and depolarizing effect on adult-born DGCs, which increases their maturation and synaptic integration. Importantly, to augment adult-born DGC synaptic integration, stimulation by GABAergic interneurons must occur transiently during the period of highest adult-born DGC sensitivity, the so-called critical period of these cells. Thus, it can be hypothesized that the basal tonic increase in the levels of GABAergic innervation that occurs in the DG of Tau ${ }^{\mathrm{VLW}}$ mice prevents the phasic effects of GABA release in response to EE.
A transient increase in the excitability of adult-born DGCs, achieved through chemoactivation during their critical period increases the morphological and functional maturation of this cell population in WT animals and emulates the effects of EE (Alvarez et al., 2016). Here, we sought to determine whether chemoactivation of adult-born DGCs during their critical period counteracts the alterations observed in Tau ${ }^{\mathrm{VLW}}$ mice. Importantly, chemoactivation was observed to increase the morphological complexity of adult-born DGCs in WT animals and to normalize the aberrant morphology and afferent connectivity of these cells in Tau ${ }^{\mathrm{VLW}}$ mice. To the best of our knowledge, this study is the first to test the therapeutic potential of applying chemoactivation to adult-born DGCs in a mouse model of a neurodegenerative disease. Our data point to chemoactivation as a diseasemodifying strategy that can reverse the alterations observed in the adult-born DGCs of this FTD model.

\section{References}

Alexander GM, Rogan SC, Abbas AI, Armbruster BN, Pei Y, Allen JA, Nonneman RJ, Hartmann J, Moy SS, Nicolelis MA, McNamara JO, Roth BL (2009) Remote control of neuronal activity in transgenic mice expressing evolved G protein-coupled receptors. Neuron 63:27-39.

Allen B, Ingram E, Takao M, Smith MJ, Jakes R, Virdee K, Yoshida H, Holzer M, Craxton M, Emson PC, Atzori C, Migheli A, Crowther RA, Ghetti B, Spillantini MG, Goedert M (2002) Abundant tau filaments and nonapoptotic neurodegeneration in transgenic mice expressing human P301S tau protein. J Neurosci 22:9340-9351.

Alonso Adel C, Mederlyova A, Novak M, Grundke-Iqbal I, Iqbal K (2004) Promotion of hyperphosphorylation by frontotemporal dementia tau mutations. J Biol Chem 279:34873-34881.

Altman J, Das GD (1965) Autoradiographic and histological evidence of postnatal hippocampal neurogenesis in rats. J Comp Neurol 124:319335.

Alvarez DD, Giacomini D, Yang SM, Trinchero MF, Temprana SG, Büttner KA, Beltramone N, Schinder AF (2016) A disynaptic feedback network activated by experience promotes the integration of new granule cells. Science 354:459-465.

Bandopadhyay R, Liu JY, Sisodiya SM, Thom M (2014) A comparative study of the dentate gyrus in hippocampal sclerosis in epilepsy and dementia. Neuropathol Appl Neurobiol 40:177-190.

Bell KF, de Kort GJ, Steggerda S, Shigemoto R, Ribeiro-da-Silva A, Cuello AC (2003) Structural involvement of the glutamatergic presynaptic boutons in a transgenic mouse model expressing early onset amyloid pathology. Neurosci Lett 353:143-147.

Bergami M, Masserdotti G, Temprana SG, Motori E, Eriksson TM, Göbel J, Yang SM, Conzelmann KK, Schinder AF, Götz M, Berninger B (2015) A critical period for experience-dependent remodeling of adult-born neuron connectivity. Neuron 85:710-717.

Bird TD, Nochlin D, Poorkaj P, Cherrier M, Kaye J, Payami H, Peskind E, Lampe TH, Nemens E, Boyer PJ, Schellenberg GD (1999) A clinical pathological comparison of three families with frontotemporal dementia and identical mutations in the tau gene (P301L). Brain 122:741-756.

Blasco-Ibañez JM, Freund TF (1997) Distribution, ultrastructure, and connectivity of calretinin-immunoreactive mossy cells of the mouse dentate gyrus. Hippocampus 7, 307-320.

Bolós M, Pallas-Bazarra N, Terreros-Roncal J, Perea JR, Jurado-Arjona J, Ávila J, Llorens-Martín M (2017a) Soluble tau has devastating effects on the structural plasticity of hippocampal granule neurons. Translational Psychiatry 7:1267.

Bolós M, Llorens-Martín M, Perea JR, Jurado-Arjona J, Rábano A, Hernández F, Avila J (2017b) Absence of CX3CR1 impairs the internalization of tau by microglia. Mol Neurodegener 12:59.

Braak H, Braak E (1995) Staging of Alzheimer's disease-related neurofibrillary changes. Neurobiol Aging 16:271-278; discussion 278-284.

Braak H, Alafuzoff I, Arzberger T, Kretzschmar H, Del Tredici K (2006) Staging of alzheimer disease-associated neurofibrillary pathology using paraffin sections and immunocytochemistry. Acta Neuropathol 112:389404.

Brown J, Cooper-Kuhn CM, Kempermann G, Van Praag H, Winkler J, Gage FH, Kuhn HG (2003) Enriched environment and physical activity stim- 
ulate hippocampal but not olfactory bulb neurogenesis. Eur J Neurosci 17:2042-2046.

Buée L, Hamdane M, Delobel P, Sambo AV, Bégard S, Ghestem A, Sergeant N, Delacourte A (2002) Tau story: from frontotemporal dementia to other tauopathies. J Soc Biol 196:103-108.

Chang HT, Cortez S, Vonsattel JP, Stopa EG, Schelper RL (2004) Familial frontotemporal dementia: a report of three cases of severe cerebral atrophy with rare inclusions that are negative for tau and synuclein, but positive for ubiquitin. Acta Neuropathol 108:10-16.

Choi DH, Lee KH, Lee J (2016) Effect of exercise-induced neurogenesis on cognitive function deficit in a rat model of vascular dementia. Mol Med Rep 13:2981-2990.

Cooper PN, Jackson M, Lennox G, Lowe J, Mann DM (1995) Tau, ubiquitin, and alpha B-crystallin immunohistochemistry define the principal causes of degenerative frontotemporal dementia. Arch Neurol 52:1011-1015.

Deshpande A, Bergami M, Ghanem A, Conzelmann KK, Lepier A, Götz M, Berninger B (2013) Retrograde monosynaptic tracing reveals the temporal evolution of inputs onto new neurons in the adult dentate gyrus and olfactory bulb. Proc Natl Acad Sci U S A 110:E1152-1161.

Drakew A, Frotscher M, Heimrich B (1999) Blockade of neuronal activity alters spine maturation of dentate granule cells but not their dendritic arborization. Neuroscience 94:767-774.

Ellison DW, Beal MF, Mazurek MF, Bird ED, Martin JB (1986) A postmortem study of amino acid neurotransmitters in Alzheimer's disease. Ann Neurol 20:616-621.

Engel T, Goñi-Oliver P, Gomez-Ramos P, Morán MA, Lucas JJ, Avila J, Hernández F (2008) Hippocampal neuronal subpopulations are differentially affected in double transgenic mice overexpressing frontotemporal dementia and parkinsonism linked to chromosome 17 tau and glycogen synthase kinase-3beta. Neuroscience 157:772-780.

Eriksson PS, Perfilieva E, Björk-Eriksson T, Alborn AM, Nordborg C, Peterson DA, Gage FH (1998) Neurogenesis in the adult human hippocampus. Nat Med 4:1313-1317.

Ferrer I (1999) Neurons and their dendrites in frontotemporal dementia. Dement Geriatr Cogn Disord 10:55-60.

Franklin KBJ (2013) The mouse brain in stereotaxic coordinates. San Diego: Academic.

Freund TF, Buzsáki G (1996) Interneurons of the hippocampus. Hippocampus 6:347-470.

Furukawa K, D’Souza I, Crudder CH, Onodera H, Itoyama Y, Poorkaj P, Bird TD, Schellenberg GD (2000) Pro-apoptotic effects of tau mutations in chromosome 17 frontotemporal dementia and parkinsonism. Neuroreport 11:57-60.

Furukawa K, Wang Y, Yao PJ, Fu W, Mattson MP, Itoyama Y, Onodera H, D'Souza I, Poorkaj PH, Bird TD, Schellenberg GD (2003) Alteration in calcium channel properties is responsible for the neurotoxic action of a familial frontotemporal dementia tau mutation. J Neurochem 87:427436.

Gasparini L, Terni B, Spillantini MG (2007) Frontotemporal dementia with tau pathology. Neurodegener Dis 4:236-253.

Ghetti B, Murrell J, Spillantini MG (1999) Mutations in the tau gene cause frontotemporal dementia. Brain Res Bull 50:471-472.

Ghetti B, Oblak AL, Boeve BF, Johnson KA, Dickerson BC, Goedert M (2015) Invited review: frontotemporal dementia caused by microtubuleassociated protein tau gene (MAPT) mutations: a chameleon for neuropathology and neuroimaging. Neuropathol Appl Neurobiol 41:24-46.

Goedert M, Jakes R, Crowther RA (1999) Effects of frontotemporal dementia FTDP-17 mutations on heparin-induced assembly of tau filaments. FEBS Lett 450:306-311.

Goedert M, Ghetti B, Spillantini MG (2000) Tau gene mutations in frontotemporal dementia and parkinsonism linked to chromosome 17 (FTDP17). their relevance for understanding the neurogenerative process. Ann N Y Acad Sci 920:74-83.

Gomez-Nicola D, Riecken K, Fehse B, Perry VH (2014) In-vivo RGB marking and multicolour single-cell tracking in the adult brain. Sci Rep 4:7520.

Götz J, Chen F, Barmettler R, Nitsch RM (2001) Tau filament formation in transgenic mice expressing P301L tau. J Biol Chem 276:529-534.

Govindpani K, Calvo-Flores Guzmán B, Vinnakota C, Waldvogel HJ, Faull RL, Kwakowsky A (2017) Towards a better understanding of GABAergic remodeling in Alzheimer's disease. Int J Mol Sci 18:E1813.

International Society for Biological and Environmental Repositories (2012)
2012 best practices for repositories collection, storage, retrieval, and distribution of biological materials for research international society for biological and environmental repositories. Biopreserv Biobank 10:79-161.

Ittner LM, Götz J (2011) Amyloid-beta and tau-a toxic pas de deux in Alzheimer's disease. Nat Rev Neurosci 12:65-72.

Ittner LM, Ke YD, Delerue F, Bi M, Gladbach A, van Eersel J, Wölfing H, Chieng BC, Christie MJ, Napier IA, Eckert A, Staufenbiel M, Hardeman E, Götz J (2010) Dendritic function of tau mediates amyloid-beta toxicity in Alzheimer's disease mouse models. Cell 142:387-397.

Jicha GA, Rockwood JM, Berenfeld B, Hutton M, Davies P (1999) Altered conformation of recombinant frontotemporal dementia-17 mutant tau proteins. Neurosci Lett 260:153-156.

Kelsch W, Lin CW, Lois C (2008) Sequential development of synapses in dendritic domains during adult neurogenesis. Proc Natl Acad Sci U S A 105:16803-16808.

Kelsch W, Sim S, Lois C (2010) Watching synaptogenesis in the adult brain. Annu Rev Neurosci 33:131-149.

Kempermann G, Kuhn HG, Gage FH (1997) More hippocampal neurons in adult mice living in an enriched environment. Nature 386:493-495.

Komuro Y, Xu G, Bhaskar K, Lamb BT (2015) Human tau expression reduces adult neurogenesis in a mouse model of tauopathy. Neurobiol Aging 36:2034-2042.

Kozorovitskiy Y, Gould E (2004) Dominance hierarchy influences adult neurogenesis in the dentate gyrus. J Neurosci 24:6755-6759.

Kuhn HG, Cooper-Kuhn CM, Boekhoorn K, Lucassen PJ (2007) Changes in neurogenesis in dementia and alzheimer mouse models: are they functionally relevant? Eur Arch Psychiatry Clin Neurosci 257:281-289.

Laakso MP, Frisoni GB, Könönen M, Mikkonen M, Beltramello A, Geroldi C, Bianchetti A, Trabucchi M, Soininen H, Aronen HJ (2000) Hippocampus and entorhinal cortex in frontotemporal dementia and Alzheimer's disease: a morphometric MRI study. Biol Psychiatry 47:1056-1063.

Lazarov O, Marr RA (2010) Neurogenesis and Alzheimer's disease: at the crossroads. Exp Neurol 223:267-281.

Lazarov O, Marr RA (2013) Of mice and men: neurogenesis, cognition and Alzheimer's disease. Front Aging Neurosci 5:43.

Lewis J, McGowan E, Rockwood J, Melrose H, Nacharaju P, Van Slegtenhorst M, Gwinn-Hardy K, Paul Murphy M, Baker M, Yu X, Duff K, Hardy J, Corral A, Lin WL, Yen SH, Dickson DW, Davies P, Hutton M (2000) Neurofibrillary tangles, amyotrophy and progressive motor disturbance in mice expressing mutant (P301L) tau protein. Nat Genet 25:402-405.

Li G, Lv J, Wang J, Wan P, Li Y, Jiang H, Jin Q (2016) GABAB receptors in the hippocampal dentate gyrus are involved in spatial learning and memory impairment in a rat model of vascular dementia. Brain Res Bull 124: $190-197$.

Lim F, Hernández F, Lucas JJ, Gómez-Ramos P, Morán MA, Avila J (2001) FTDP-17 mutations in tau transgenic mice provoke lysosomal abnormalities and tau filaments in forebrain. Mol Cell Neurosci 18:702-714.

Llorens-Martín M, Torres-Aleman I, Trejo JL (2006) Pronounced individual variation in the response to the stimulatory action of exercise on immature hippocampal neurons. Hippocampus 16:480-490.

Llorens-Martín M, Torres-Alemán I, Trejo JL (2009) Mechanisms mediating brain plasticity: IGF1 and adult hippocampal neurogenesis. Neuroscientist 15:134-148.

Llorens-Martín M, Tejeda GS, Trejo JL (2010) Differential regulation of the variations induced by environmental richness in adult neurogenesis as a function of time: a dual birthdating analysis. PLoS One 5:e12188.

Llorens-Martín M, Hernández F, Avila J (2011) Expression of frontotemporal dementia with parkinsonism associated to chromosome 17 tau induces specific degeneration of the ventral dentate gyrus and depressive-like behavior in mice. Neuroscience 196:215-227.

Llorens-Martín M, Fuster-Matanzo A, Teixeira CM, Jurado-Arjona J, Ulloa F, Defelipe J, Rábano A, Hernández F, Soriano E, Avila J (2013) GSK-3beta overexpression causes reversible alterations on postsynaptic densities and dendritic morphology of hippocampal granule neurons in vivo. Molecular Psychiatry 18:451-460.

Llorens-Martín M, Jurado-Arjona J, Avila J, Hernández F (2015) Novel connection between newborn granule neurons and the hippocampal CA2 field. Exp Neurol 263:285-292.

Lugert S, Basak O, Knuckles P, Haussler U, Fabel K, Götz M, Haas CA, Kempermann G, Taylor V, Giachino C (2010) Quiescent and active hippocampal neural stem cells with distinct morphologies respond selec- 
tively to physiological and pathological stimuli and aging. Cell Stem Cell 6:445-456.

Mai JM, Paxinos G (2015) Atlas of the human brain, Ed 3. San Diego: Academic.

Martínez-Martín P, Avila J (2010) Alzheimer center reina sofia foundation: fighting the disease and providing overall solutions. J Alzheimers Dis 21:337-348.

Mitew S, Kirkcaldie MT, Dickson TC, Vickers JC (2013) Altered synapses and gliotransmission in Alzheimer's disease and AD model mice. Neurobiol Aging 34:2341-2351.

Montejo de Garcini E, de la Luna S, Dominguez JE, Avila J (1994) Overexpression of tau protein in COS-1 cells results in the stabilization of centrosome-independent microtubules and extension of cytoplasmic processes. Mol Cell Biochem 130:187-196.

Moreno-Jiménez EP, Flor-García M, Terreros-Roncal J, Rábano A, Cafini F, Pallas-Bazarra N, Ávila J, Llorens-Martín M (2019) Adult hippocampal neurogenesis is abundant in neurologically healthy subjects and drops sharply in patients with Alzheimer's disease. Nat Med 25:554-560.

Mountjoy CQ, Rossor MN, Iversen LL, Roth M (1984) Correlation of cortical cholinergic and GABA deficits with quantitative neuropathological findings in senile dementia. Brain 107:507-518.

Nilsen LH, Rae C, Ittner LM, Götz J, Sonnewald U (2013) Glutamate metabolism is impaired in transgenic mice with tau hyperphosphorylation. J Cereb Blood Flow Metab 33:684-691.

Nishimura A, Ikemoto K, Satoh K, Yamamoto Y, Rand S, Brinkmann B, Nishi K (2000) The carbohydrate deposits detected by histochemical methods in the molecular layer of the dentate gyrus in the hippocampal formation of patients with schizophrenia, Down's syndrome and dementia, and aged person. Glycoconj J 17:815-822.

Oliva R (2000) Genetics of frontotemporal dementia and alterations of the tau gene. Neurologia 15:33-37.

Pallas-Bazarra N, Jurado-Arjona J, Navarrete M, Esteban JA, Hernández F, Ávila J, Llorens-Martín M (2016) Novel function of tau in regulating the effects of external stimuli on adult hippocampal neurogenesis. EMBO J 35:1417-1436.

Pallas-Bazarra N, Kastanauskaite A, Avila J, DeFelipe J, Llorens-Martín M (2017) GSK-3beta overexpression alters the dendritic spines of developmentally generated granule neurons in the mouse hippocampal dentate gyrus. Front Neuroanat 11:18.

Rodriguez A, Ehlenberger DB, Dickstein DL, Hof PR, Wearne SL (2008) Automated three-dimensional detection and shape classification of dendritic spines from fluorescence microscopy images. PLoS One 3:e1997.

Rubinsztein DC (2016) Tau toxicity feeds forward in frontotemporal dementia. Nat Med 22:24-25.

Sah N, Peterson BD, Lubejko ST, Vivar C, van Praag H (2017) Running reorganizes the circuitry of one-week-old adult-born hippocampal neurons. Sci Rep 7:10903.

Sahay A, Hen R (2007) Adult hippocampal neurogenesis in depression. Nat Neurosci 10:1110-1115.

Sahay A, Scobie KN, Hill AS, O'Carroll CM, Kheirbek MA, Burghardt NS, Fenton AA, Dranovsky A, Hen R (2011) Increasing adult hippocampal neurogenesis is sufficient to improve pattern separation. Nature 472:466-470.

Schambach A, Mueller D, Galla M, Verstegen MM, Wagemaker G, Loew R, Baum C, Bohne J (2006) Overcoming promoter competition in packaging cells improves production of self-inactivating retroviral vectors. Gene Ther 13:1524-1533.

Schindowski K, Belarbi K, Bretteville A, Ando K, Buée L (2008) Neurogen- esis and cell cycle-reactivated neuronal death during pathogenic tau aggregation. Genes Brain Behav 7:92-100.

Senut MC, Roudier M, Davous P, Fallet-Bianco C, Lamour Y (1991) Senile dementia of the alzheimer type: is there a correlation between entorhinal cortex and dentate gyrus lesions? Acta Neuropathol 82:306-315.

Shiarli AM, Jennings R, Shi J, Bailey K, Davidson Y, Tian J, Bigio EH, Ghetti B, Murrell JR, Delisle MB, Mirra S, Crain B, Zolo P, Arima K, Iseki E, Murayama S, Kretzschmar H, Neumann M, Lippa C, Halliday G, et al. (2006) Comparison of extent of tau pathology in patients with frontotemporal dementia with parkinsonism linked to chromosome 17 (FTDP17), frontotemporal lobar degeneration with pick bodies and early onset Alzheimer's disease. Neuropathol Appl Neurobiol 32:374-387.

Spalding KL, Bergmann O, Alkass K, Bernard S, Salehpour M, Huttner HB, Bostrom E, Westerlund I, Vial C, Buchholz BA, Possnert G, Mash DC, Druid H, Frisén J (2013) Dynamics of hippocampal neurogenesis in adult humans. Cell 153:1219-1227.

Spillantini MG, Goedert M (2000) Tau mutations in familial frontotemporal dementia. Brain 123:857-859.

Spillantini MG, Goedert M (2001) Tau gene mutations and tau pathology in frontotemporal dementia and parkinsonism linked to chromosome 17. Adv Exp Med Biol 487:21-37.

Temprana SG, Mongiat LA, Yang SM, Trinchero MF, Alvarez DD, Kropff E, Giacomini D, Beltramone N, Lanuza GM, Schinder AF (2015) Delayed coupling to feedback inhibition during a critical period for the integration of adult-born granule cells. Neuron 85:116-130.

Toni N, Laplagne DA, Zhao C, Lombardi G, Ribak CE, Gage FH, Schinder AF (2008) Neurons born in the adult dentate gyrus form functional synapses with target cells. Nat Neurosci 11:901-907.

van Praag H (2008) Neurogenesis and exercise: past and future directions. Neuromolecular Med 10:128-140.

van Praag H (2009) Exercise and the brain: something to chew on. Trends Neurosci 32:283-290

van Praag H, Kempermann G, Gage FH (2000) Neural consequences of environmental enrichment. Nat Rev Neurosci 1:191-198.

van Praag H, Schinder AF, Christie BR, Toni N, Palmer TD, Gage FH (2002) Functional neurogenesis in the adult hippocampus. Nature 415:10301034.

Vivar C, Potter MC, Choi J, Lee JY, Stringer TP, Callaway EM, Gage FH, Suh $\mathrm{H}$, van Praag H (2012) Monosynaptic inputs to new neurons in the dentate gyrus. Nat Commun 3:1107.

Wickersham IR, Finke S, Conzelmann KK, Callaway EM (2007a) Retrograde neuronal tracing with a deletion-mutant rabies virus. Nat Methods 4:47-49.

Wickersham IR, Lyon DC, Barnard RJ, Mori T, Finke S, Conzelmann KK, Young JA, Callaway EM (2007b) Monosynaptic restriction of transsynaptic tracing from single, genetically targeted neurons. Neuron 53:639647.

Wu Z, Guo Z, Gearing M, Chen G (2014) Tonic inhibition in dentate gyrus impairs long-term potentiation and memory in an Alzheimer's disease model. Nat Commun 5:4159.

Yoshiyama Y, Higuchi M, Zhang B, Huang SM, Iwata N, Saido TC, Maeda J, Suhara T, Trojanowski JQ, Lee VM (2007) Synapse loss and microglial activation precede tangles in a P301S tauopathy mouse model. Neuron 53:337-351.

Zhao C, Teng EM, Summers RG Jr, Ming GL, Gage FH (2006) Distinct morphological stages of dentate granule neuron maturation in the adult mouse hippocampus. J Neurosci 26:3-11. 